\title{
Spent equilibrium catalyst as internal curing agent in UHPFRC
}

\author{
Ana Mafalda Matos ${ }^{\mathrm{a}}$, Sandra Nunes ${ }^{\mathrm{a}, *}$, Carla Costa ${ }^{\mathrm{b}}$, José L. Barroso-Aguiar ${ }^{\mathrm{c}}$ \\ ${ }^{\text {a }}$ CONSTRUCT-LABEST, University of Porto, Portugal \\ ${ }^{\mathrm{b}}$ High Institute of Engineering of Lisbon (ISEL), Lisbon Polytechnic Institute, Portugal \\ ${ }^{\mathrm{c}}$ Department of Civil Engineering, University of Minho, Guimarães, Portugal
}

\section{A R T I C L E I N F O}

\section{Keywords:}

Ultra-high performance fibre reinforced

cementitious composites (UHPFRC)

Spent equilibrium catalyst (ECat)

Statistical factorial design

Autogenous shrinkage

Durability

Sustainability

\begin{abstract}
A B S T R A C T
The main goal of the current paper is to optimize ultra-high performance cementitious material (UHPC) mixes incorporating the spent equilibrium catalyst (ECat) to mitigate autogenous shrinkage. Design of experiments approach was used to optimize mixtures targeting different engineering properties, namely, self-compactibility, low early-age shrinkage and cracking risk, improved durability and high mechanical performance. The statistical models established indicated that ECat exhibits a strong positive effect on the autogenous shrinkage mitigation of UHPC attributed to the water absorbed in the porous of ECat particles. The proposed optimal UHPC mixture represents the best compromise between low autogenous shrinkage $-32 \%$ of reduction - and high resistivity at 28 days without impairing self-compatibility and compressive strength. This optimal UHPC combined with $3 \%$ high-strength steel fibres $\left(\mathrm{l}_{\mathrm{f}} / \mathrm{d}_{\mathrm{f}}=65\right)$ proved to be comparable to other Ultra High-Performance Fibre Reinforced Composites (UHPFRC), in terms of mechanical behaviour, and more eco-friendly and cost-efficient than UHPCs reported in the literature.
\end{abstract}

\section{Introduction}

Ultra-High Performance Fibre Reinforced Composite (UHPFRC) has become one of the promising cementitious materials for the next generation of infrastructures - that need to be more resilient and sustainable - because of its outstanding mechanical properties, excellent durability characteristics, and good workability [1]. UHPFRC refers to the family of composite materials containing a large amount of short steel fibres evenly embedded in an ultra-compact cementitious matrix (hereafter, UHPC) with a high content of the binding phase including cement and supplementary cementitious materials (SCMs), commonly silica fume, and a very low water to binder ratio $(\mathrm{w} / \mathrm{b}<0.2)$ [2]. However, the typical high amount of cement $\left(700-850 \mathrm{~kg} / \mathrm{m}^{3}\right)$ and silica fume (SF) ( $>20 \%$ of cement content) present in the UHPFRC mixtures [3] cause some drawbacks, in terms of the limited availability of SF, especially in developing countries, the concretes high production cost, and in the early-ages properties namely due to adverse effects on the heat of hydration and dimensional stability.

The replacement of part of the cement clinker with additions such as SCMs is an interesting solution to reduce the cement content, and it contributes to sustainable development [4]. This is particularly relevant in the case of UHPFRC considering the fact that a significant quantity of cement clinker remains unhydrated [5] (thus acting as a filler material), due to its very low water to binder ratio. Many SCMs other than SF have been successfully incorporated in UHPFRC such as pulverized fly ash, ground granulated blast furnace slag, metakaolin, steel slag powder, rice husk ash, and nanoparticles (nano- $\mathrm{SiO}_{2}$, nano- $\mathrm{CaCO}_{3}$, nano- $-\mathrm{TiO}_{2}$, nano- $\mathrm{Fe}_{2} \mathrm{O}_{3}$, etc.), as well as limestone filler, as reported in a review paper by Shi et al. [2]. The use of locally available additions is a key factor to save energy, reduce cost and decrease $\mathrm{CO}_{2}$ emissions from the production of UHPFRC. From this perspective, the incorporation of limestone filler in UHPFRC is expected to have few limitations to implement, because it is a global available raw material, it involves modest changes in existing production lines, and it requires no new quarries nor large investments [6]. A new concept of UHPFRC production using limestone filler as a partial cement surrogate was first developed at MCS-EPFL within ARCHES project, aiming to make the application of UHPFRC technology feasible with a wide range of cements and superplasticisers [7]. Huang et al. reported that partial replacement of cement with limestone $\left(D_{50}=8 \mu \mathrm{m}\right)$, up to $54 \%$, is beneficial for the workability and compressive strength of UHPC [8]. By incorporating limestone filler in UHPC, the hydration degree increased from $39 \%$ to $66 \%$, due to the facilitation of the nucleation and growth of outer C-S-H [8].

$\mathrm{SF}$ is a principal constituent material in UHPC, which main beneficial effects include: (1) the filling effect, significantly improving the

\footnotetext{
* Corresponding author.

E-mail addresses: ana.matos@fe.up.pt (A.M. Matos), snunes@fe.up.pt (S. Nunes), carlacosta@dec.isel.pt (C. Costa), aguiar@civil.uminho.pt (J.L. Barroso-Aguiar).
} 


List of abbreviations
$\begin{array}{ll}V_{E C a t} / V_{S} & \text { ECat to sand volume ratio } \\ S p / p & \text { Superplasticizer to powder weight ratio } \\ S f / c & \text { Silica fume to cement weight ratio } \\ \left(V_{w} / V_{p}\right) & \text { Water to powder volume ratio } \\ \text { a_shr_20 hAutogenous shrinkage deformation } 20 \mathrm{~h} \text { after final setting } & \\ & \text { time }(\mu \mathrm{m} / \mathrm{m}) \\ \rho_{-} 28 \mathrm{~d} & \text { Electrical resistivity at } 28 \text { age days }(\Omega . \mathrm{m}) \\ \text { ANOVA } & \text { Analysis of variance } \\ \text { BET } & \text { Brunauer-Emmett-Teller theory for the measurement of } \\ & \text { the specific surface area of materials } \\ \text { CCD } & \text { Central composite design } \\ \text { Dflow } & \text { Spread flow diameter (mm) } \\ \text { DOE } & \text { Design of experiments } \\ \text { ECat } & \text { Spent equilibrium catalyst } \\ \text { FCC } & \text { Fluid Catalytic Cracking } \\ \text { GWP } & \text { Global Warming Potential }\end{array}$

$\begin{array}{ll}\text { ITZ } & \text { Interfacial transition zone } \\ \text { LF } & \text { Limestone filler } \\ \text { LVDT } & \text { Linear variable differential transformer } \\ \text { LWS } & \text { Lightweight sand } \\ \text { Rc_28d } & \text { Compressive strength at 28 age days (MPa) } \\ \text { RH } & \text { Relative humidity } \\ \text { RHA } & \text { Rice husk ash } \\ \text { SAPs } & \text { Superabsorbent polymers } \\ \text { SCMs } & \text { Supplementary cementitious materials } \\ \text { SEM } & \text { Scanning electron microscopy } \\ \text { SF } & \text { Silica fume } \\ \text { Sp } & \text { Superplasticizer } \\ \text { tf } & \text { Final setting time (h) } \\ \text { UHPC } & \text { Cementitious matrix of an UHPFRC } \\ \text { UHPFRC } & \text { Ultra-High Performance Fibre Reinforced Composite } \\ \text { UTT } & \text { Uniaxial tensile test } \\ \text { w/c } & \text { Water to cement weight ratio }\end{array}$

packing density of the system and the interfacial transition zone (ITZ) between the binding paste and aggregates; (2) the lubricating effect, resulting from the spherical shape of its particles leading to improved workability; and (3) the pozzolanic effect, contributing to produce additional hydration products and, thus, enhancing strength and durability [9]. However, since SF is an industrial by-product its availability is limited, and due to an increasing demand for good quality SF in the construction industry, it becomes rather expensive. These motivated some research studies on alternative very reactive SCMs, such as rice husk ash (RHA) [6], metakaolin [10], and fine glass powder [11]. Tuan [9] reported that there is a synergistic effect between RHA and SF on the workability and the compressive strength of UHPFRC. The best combination regarding compressive strength and workability was obtained with 10\% RHA and 10\% SF [9]. Another important positive effect of RHA addition is the mitigation of autogenous shrinkage, due to its water absorption capacity in the porous structure [9].

UHPC exhibits large shrinkage values, but, unlike conventional concrete, autogenous shrinkage represents the largest portion of the total shrinkage in UHPC (from $75 \%$ up to $100 \%$ depending on the mixture) [3]. Moreover, this phenomenon occurs in the first one or two days after casting, being possible to show deformations of around $1000 \mu \mathrm{m} / \mathrm{m}$ in $24 \mathrm{~h} \mathrm{[12].} \mathrm{This} \mathrm{very} \mathrm{high} \mathrm{autogenous} \mathrm{shrinkage} \mathrm{of} \mathrm{UHPC}$ is due to its very low w/b ratio and very high content of SF which causes a significant drop in the internal relative humidity ( $\mathrm{RH})$ in the cement paste during the hardening process that leads to the occurrence of self-desiccation in the absence of an external source of water [13]. After mixing, when a layer of fresh UHPFRC is applied over an existing concrete, the restriction conferred by the substrate to the new layer deformation generates internal tensile stresses. The magnitude of these internal stresses depends on the development of material properties during early ages, namely, the magnitude and evolution of shrinkage, tensile creep and the evolution of the Young's modulus of elasticity. When UHPFRC exhibits significant strain hardening behaviour in tension only very fine micro-cracks can occur [14]. Nevertheless, in zones with lower fibre content or unfavourable fibres orientation [14] larger cracks might occur in the UHPFRC layer, which might impair the longterm performance of UHPFRC. For these reasons, several attempts have been made to mitigate the autogenous shrinkage of UHPFRC.

To counteract the significant drop in the internal RH in the cement paste during the hardening and, thus, the self-desiccation, several strategies of internal curing have been proposed for UHPC, including the use of saturated lightweight sand [15], superabsorbent polymers (SAPs) [16-18], recycled coral-based materials [19,20], and rice husk [9]. Meng and Khayat [15] employed pre-saturated lightweight sand (LWS) (nominal size of $4.75 \mathrm{~mm}$ ) as an internal curing agent to prepare
UHPC. The optimum LWS/natural sand ratio was found to be $25 \%$, resulting in a compressive strength of $158 \mathrm{MPa}$ and autogenous shrinkage limited to $365 \mu \mathrm{m} / \mathrm{m}$, at 28 days. Incorporation of pre-saturated LWS was also found to promote cement hydration and reduce total porosity [15]. Dudziak and Mechtcherine [17] showed that the use of SAPs and additional water during mixing leads to a reduction in deformation due to autogenous shrinkage, with a consequent positive effect on the generated tensile stresses at very early ages. The addition of $0.3 \%$ SAP by mass of cement plus extra water resulted in a reduction of about $30 \%$ in autogenous shrinkage after one day of measurement. A further reduction in the magnitude of autogenous shrinkage deformations can be achieved with increasing dosages of SAP and extra water [17]. However, SAPs lead to the formation of voids, initially filled with water and subsequently dried out, which might negatively affect compressive strength [17]. In order to minimize the negative impact of the large pores on concrete strength, smaller size SAPs (a solution-polymerized SAP with a particle size $<63 \mu \mathrm{m}$ in the dry state) were employed by Justs et al. [18]. This allowed to reach compressive strengths of almost $150 \mathrm{MPa}$ at 28 days as well as to extend cement hydration further beyond the stage when there is no free capillary pore space for precipitation of hydration products, thanks to the additional space introduced by the SAP. Wang et al. [19] found that addition of recycled coral-based materials (micro-coral sand and/or coral sand) is effective in decreasing the autogenous shrinkage of UHPC, which can be attributed to the internal curing provided by the porous structure of the coral. A different strategy for internal curing was followed by Tuan [9], by incorporating RHA $(5-10 \mu \mathrm{m})$ in UHPC. Due to its porous structure, RHA particles may absorb a certain amount of free water during mixing ( $20 \%$, by mass, of RHA content [9]), acting as "micro water reservoirs". The absorbed water in RHA particles can compensate the drop of relative humidity in cement paste during the hydration of cement, therefore, contributing to mitigate the high autogenous shrinkage of UHPC [21] as well as to improve the cement paste microstructure due to a long-lasting pozzolanic reaction of RHA [21]. However, the geographical availability of RHA is very limited namely in Portugal is almost null. Thus, the research team searched for alternative materials, especially industrial by-products locally available that might reveal similar behaviour. A potential candidate to internal curing agent is the spent equilibrium catalyst (ECat), a waste generated by the oil refinery industry since it exhibits high water absorption ability and, moreover, is also a pozzolanic material.

The equilibrium catalyst is used in the Fluid Catalytic Cracking (FCC) process during the conversion of low-value heavy gas oils into more valuable lighter compounds, namely gasoline [22,23]. During this process, the catalyst loses adequate levels of activity and selectivity and 
has to be removed from the process giving rise to a waste [24] which is mainly disposal of in landfills. Every year, the oil industry generates about 840000 tonnes ECat/year [25] of which 1700 tonnes of ECat/ year in Portugal. The ECat is a white-grey fine powder (with a typical particle size of $75 \mu \mathrm{m}$ ) mainly comprising four components: an aluminosilicate faujasite-type zeolite; an essentially amorphous alumina matrix which is also catalytically active; a clay, usually kaoline; and a binder that provides physical integrity to the catalyst [23]. The exact composition of this catalyst depends on the manufacturer because it is specially designed to meet the specific requirements of the FCC unit is going to be used and its typical oil feedstock. Due to its aluminosilicate chemical composition and a very high specific surface $\left(>100 \mathrm{~m}^{2} / \mathrm{g}\right)$ [23] (mainly provided by the zeolite and matrix constituents), ECat has a potential pozzolanic activity.

Previous studies revealed that ECat can be used as SCM partially replacing either cement $(10-20 \%$, by mass) $[26-28,51]$ or sand (ca. $10 \%$, by mass) $[29,30]$ in both traditional and self-compacting mortars and concrete, contributing typically to an improvement of overall performance including durability $[31,32]$ although contributing to decrease the flowability of the cement-based materials in the fresh state $[26,28,30,33]$. Torregrosa [34] incorporated an ECat $\left(D_{50}=10 \mu \mathrm{m}\right.$, i.e smaller than typical) in UHPC/UHPFRC as a partial or total surrogate of silica fume. The results of this study showed that the ECat led to a decrease in the workability of UHPC mixtures in the fresh state but less marked than that promoted by similar content of SF. Moreover, although the difference between compressive strength of ECat and SF UHPC mixtures with 2 days was not noticeable, at 7 and 28 days ECat mixtures revealed higher strength than that of SF mixtures. Since this difference was more remarkable in the mixtures with 7 days the ECat's pozzolanic reaction was faster than that of SF. Concerning the flexural strength, the differences between the use of ECat or condensed SF were not very significant [34]. However, the influence of ECat on autogenous shrinkage and durability of UHPFRC remains unreported.

In the current study, for the best of authors knowledge, ECat is for the first time used as an internal curing agent to produce UHPFRC, aiming to reduce its autogenous shrinkage without impairing mechanical properties and durability. To achieve this goal a central composite design (CCD) was utilized to determine the optimum combination of powder materials (cement, silica fume and limestone filler), aggregates (fine sand and ECat) and superplasticizer in UHPC production. The water to cement weight ratio was constant of 0.25 , and the partial replacement of the fine sand with ECat was kept within the range of $0-30 \%$, by volume. UHPC mixtures were assessed regarding their deformability, setting time, autogenous shrinkage, resistivity and compressive strength. Regression models were derived and validated, which allow predicting selected properties of UHPC, along with the identification of the most significant effects of mixture parameters on each property of UHPC. After optimising the matrix, short steel fibres ( $3 \%$ by volume) were incorporated in UHPC and the performance of the resulting UHPFRC was further investigated by analysing its flowability, autogenous shrinkage evolution, mechanical performance, cost and environmental efficiency.

\subsection{Research significance}

Considering the concept of hybrid structures where thin layers of UHPFRC are applied in the critical locations in terms of environmental exposure and mechanical demand [35], applicable to the rehabilitation/strengthening of the existing infrastructures, controlling the cracking risk of UHPC at early ages is essential for ensuring an enhanced long-term performance and longer service life. Reducing the early-age shrinkage is one way to improve the resistance to microcracking of UHPFRC. Besides reducing autogenous shrinkage, the use of spent equilibrium catalyst (ECat) in UHPC, as an internal curing agent, has the potential to enhance hydration due to more availability of water in the system and the pozzolanic activity of ECat. This can allow

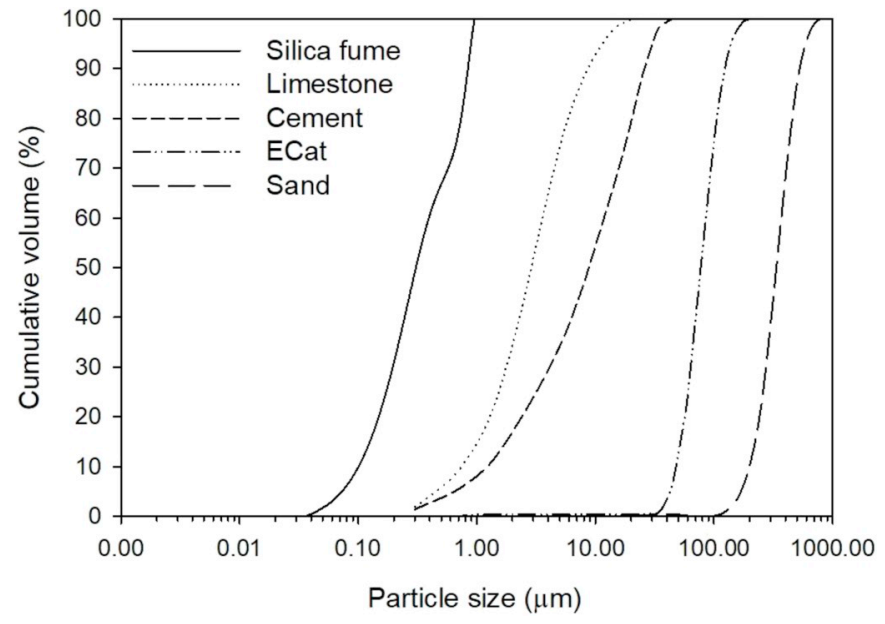

Fig. 1. Particle size distribution of all solid materials.

achieving new UHPC mixtures with comparable performance but lower cement content, which brings advantages regarding cost and $\mathrm{CO}_{2}$ emissions. Moreover, the possibility of replacing natural sand with a residue generated by the oil refinery industry allows both limiting the excessive exploitation of naturally occurring river sand and a waste recycling that is diverted away from landfills.

\section{Materials and methods}

\subsection{Raw materials}

UHPC were produced using the following solid materials: Type I Portland cement (CEM I 42.5 R, complying with EN 197-1); limestone filler (LF); silica fume (SF); equilibrium catalyst (ECat) generated by Sines Refinery, Portugal, and siliceous natural sand. Fig. 1 shows the particle size distribution (PSD) of all solid materials. The PSD of the sand was obtained following the standard EN 933-1, the PSD of SF was determined by Transmission Electron Microscopy, and the PSDs of the remaining solid materials were obtained by laser diffraction. ECat possesses a narrow particle size range, around $80 \mu \mathrm{m}$, in between cement and sand curves.

Table 1 summarizes the relevant chemical and physical properties of cement, LF, ECat and SF. The bulk chemical compositions were obtained by X-ray fluorescence spectrometry (XRF), and the loss on ignition (LOI) was evaluated following EN 196-2. Density of cement and LF was obtained according to Portuguese LNEC specification E-64 [36]; the density of ECat was determined according to EN 1097-6. Although the Blaine method is often used to assess the cement specific surface area, the BET method is more appropriate to determine the specific surface area of ECat since, particularly due to its zeolite constituent, it is a highly microporous material (as shown in Fig. 2) in which most of the surface area is internal and, therefore, only accessible using nitrogen adsorption-desorption. The high specific surface of the ECat $\left(150070 \mathrm{~m}^{2} / \mathrm{Kg}\right)$ with water affinity explains its significant water absorption. The $24 \mathrm{~h}$ water absorption of ECat is $30 \%$, by mass, at saturated surface-dry basis, according to the standard EN 1097-6. A similar absorption capacity was found by Su et al. [30]. ECat's water absorption (30\% by mass) was taken into account in the total water added to the UHPC mixtures.

The pozzolanic reactivity of ECat and SF was assessed using the modified Chapelle test method (according to French standard NF P18513). Results reveal that 1540 and $1577 \mathrm{mg}$ of $\mathrm{Ca}(\mathrm{OH})_{2}$ are consumed per $g$ of ECat and per $g$ of SF, respectively, during the pozzolanic reaction suggesting that both materials have high pozzolanic activity.

The water absorption and density of the natural sand is $0.5 \%$ and $2570 \mathrm{~kg} / \mathrm{m}^{3}$, respectively. A polycarboxylate-based high-range water 
Table 1

Chemical and physical properties of cement, ECat, silica fume, and limestone filler.

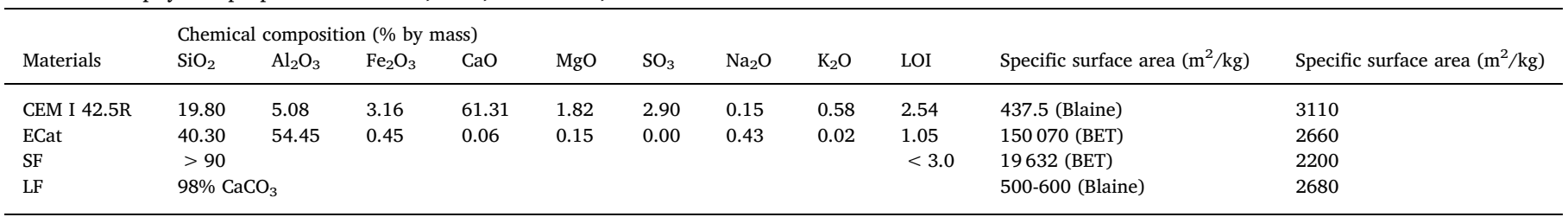

reducer (Sp) with a solid mass content of $40 \%$ and density of $1080 \mathrm{~kg} /$ $\mathrm{m}^{3}$ (Viscocrete 20HE, supplied by Sika) was used. Steel fibres with $0.2 \mathrm{~mm}$ in diameter and $13 \mathrm{~mm}$ in length $\left(\mathrm{l}_{\mathrm{f}} / \mathrm{d}_{\mathrm{f}}=65\right)$ were incorporated to produce UHPFRC. The tensile strength and modulus of elasticity of the fibres are $2750 \mathrm{MPa}$ and $200 \mathrm{GPa}$, respectively. Tap water was used, in accordance with standard EN 1008.

\subsection{Design of experiments and mixtures proportions}

UHPFRC mix design needs intensive laboratory testing to assess raw materials compatibility and to optimize mix-proportions while satisfying the several performance requirements. This is particularly relevant both when a large number of constituent materials are used, as well as, when new and unconventional materials are incorporated, such as industrial by-products.

In the current study, experiments were conducted according to a Central Composite Design (CCD) [37], one of the most common experimental designs used for modelling and optimisation of self-compacting mortar/concrete [38,39], conventional steel fibre reinforced concrete [40], and also UHPC mixtures [41-43]. The experimental factorial design approach is an efficient means to assess the influence of key mixture variables on UHPC/UHPFRC properties, being valid for a wide range of mixture proportions. It is useful to identify the main effects for the variables under study, as well as to unveil any existing interactions between those variables. Such understanding can facilitate the test protocol required to optimize UHPC, hence reduce the effort necessary to achieve the target engineering properties, namely, selfcompactability, low risk of early age cracking, durability and high mechanical performance. The Design-Expert software [44] was used to assist in following stages of the study: experiments design, statistical analysis of data, fitting of empirical models using regression analysis (performing the analysis of variance (ANOVA) and the residuals analysis) and, finally, optimisation.

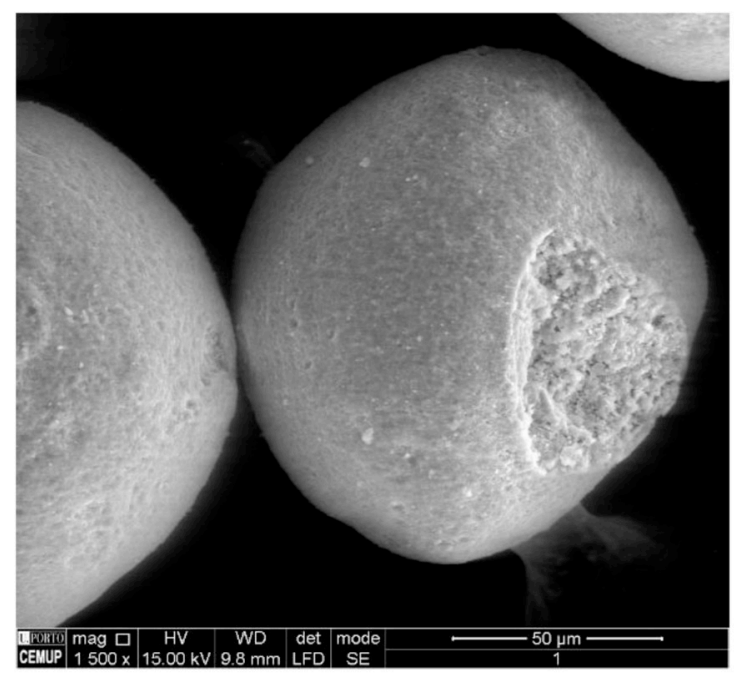

(a)
Table 2

Coded and actual values of independent variables.

\begin{tabular}{|c|c|c|c|c|c|c|}
\hline \multirow[b]{2}{*}{ Variables } & \multirow[b]{2}{*}{ Code } & \multicolumn{3}{|c|}{ Levels of variables } & \multirow[b]{2}{*}{+1} & \multirow[b]{2}{*}{+2} \\
\hline & & -2 & -1 & 0 & & \\
\hline$V_{w} / V_{p}$ & $X_{1}$ & 0.355 & 0.375 & 0.395 & 0.415 & 0.435 \\
\hline$S p / p$ & $X_{2}$ & $2.0 \%$ & $2.2 \%$ & $2.4 \%$ & $2.6 \%$ & $2.8 \%$ \\
\hline$V_{E C a t} / V_{S}$ & $X_{3}$ & 0.000 & 0.075 & 0.150 & 0.225 & 0.300 \\
\hline$s f / c$ & $X_{4}$ & 0.005 & 0.025 & 0.045 & 0.065 & 0.085 \\
\hline
\end{tabular}

Four key design variables $\left(X_{\mathrm{i}}, \mathrm{i}=1\right.$ to 4$)$ were selected to derive the regression models: water to powder volume ratio $\left(V_{w} / V_{p}\right)$; the superplasticizer to powder weight ratio $(S p / p)$; ECat to sand volume ratio $\left(V_{E C a t} / V_{s}\right)$ and $\mathrm{SF}$ to cement weight ratio $(s f / c)$. Based on a preliminary study [12] the ranges of the selected design variables were established as indicated in Table 2. The correspondence between coded and actual values of the independent variables points is also indicated in Table 2. The water to cement $(\mathrm{w} / \mathrm{c})$ weight ratio and the fine aggregate (silicious sand + ECat) content were set fixed and equal to 0.25 and $0.39 \mathrm{~m}^{3} / \mathrm{m}^{3}$, respectively.

In this study, 30 mixtures were investigated, consisting of $2^{4}$ factorial points augmented with 8 axial points, plus 6 replications of the central point. The corresponding mixture proportions are presented in Table 3. Both the contents of cement and SF in all mixtures are relatively low as compared to typical UHPFRC mixtures (see Section 1) [3]. In the current study one used far less SF than the amount theoretically required for total consumption of $\mathrm{Ca}(\mathrm{OH})_{2}$ released from cement hydration ( $18 \%$ by weight of cement, according to Ref. [45]), thus providing an opportunity for both pozzolanic materials to react but not completely in most of the cases (excepted for CC5). Given the beneficial effects of limestone filler mentioned before and its abundant availability in Portugal, an extensive range of variation in limestone filler content was allowed, from almost 0 up to $543 \mathrm{~kg} / \mathrm{m}^{3}$. The mixing water

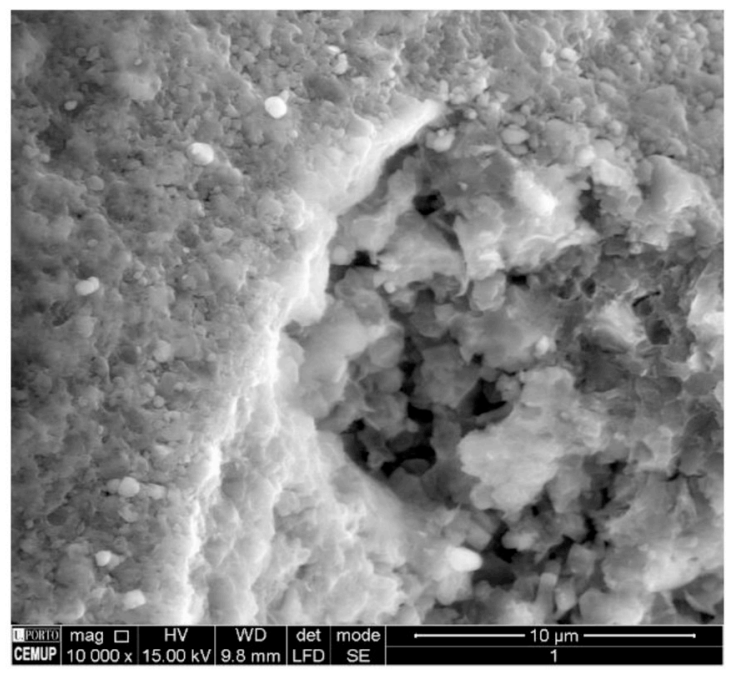

(b)

Fig. 2. Secondary electron mode SEM image of ECat's particle morphology: (a) entire particle view $(\times 1500)(b)$ external surface and internal porosity $(\times 10000)$. 
Table 3

Experimental plan and mixture proportions.

\begin{tabular}{|c|c|c|c|c|c|c|c|c|c|c|c|}
\hline \multirow[b]{2}{*}{ Ref. } & \multicolumn{4}{|c|}{ Coded variables } & \multicolumn{7}{|c|}{ Quantity $\left(\mathrm{kg} / \mathrm{m}^{3}\right)$} \\
\hline & $\mathrm{Vw} / \mathrm{Vp}$ & $\mathrm{Sp} / \mathrm{p}$ & $\mathrm{V}_{\mathrm{ECat}} / \mathrm{V}_{\mathrm{s}}$ & $\mathrm{sf} / \mathrm{c}$ & Cement & $\mathrm{LF}$ & SF & ECat & Sand & Mixing water & Sp \\
\hline $\mathrm{Ci}$ & 0 & 0 & 0 & 0 & 690.90 & 273.54 & 31.09 & 155.61 & 851.96 & 158.39 & 23.89 \\
\hline F1 & -1 & -1 & -1 & -1 & 665.45 & 453.37 & 16.64 & 77.81 & 927.13 & 151.38 & 24.98 \\
\hline $\mathrm{F} 2$ & 1 & -1 & -1 & -1 & 715.62 & 364.31 & 17.89 & 77.81 & 927.13 & 164.41 & 24.15 \\
\hline F3 & -1 & 1 & -1 & -1 & 665.45 & 453.37 & 16.64 & 77.81 & 927.13 & 148.65 & 29.52 \\
\hline F4 & 1 & 1 & -1 & -1 & 715.62 & 364.31 & 17.89 & 77.81 & 927.13 & 161.78 & 28.54 \\
\hline F5 & -1 & -1 & 1 & -1 & 665.45 & 453.37 & 16.64 & 233.42 & 776.78 & 151.38 & 24.98 \\
\hline F6 & 1 & -1 & 1 & -1 & 715.62 & 364.31 & 17.89 & 233.42 & 776.78 & 164.41 & 24.15 \\
\hline F7 & -1 & 1 & 1 & -1 & 665.45 & 453.37 & 16.64 & 233.42 & 776.78 & 148.65 & 29.52 \\
\hline F8 & 1 & 1 & 1 & -1 & 715.62 & 364.31 & 17.89 & 233.42 & 776.78 & 161.78 & 28.54 \\
\hline F9 & -1 & -1 & -1 & 1 & 665.45 & 193.96 & 43.25 & 77.81 & 927.13 & 154.45 & 19.86 \\
\hline F10 & 1 & -1 & -1 & 1 & 715.62 & 85.35 & 46.52 & 77.81 & 927.13 & 167.72 & 18.64 \\
\hline F11 & -1 & 1 & -1 & 1 & 665.45 & 193.96 & 43.25 & 77.81 & 927.13 & 152.28 & 23.47 \\
\hline F12 & 1 & 1 & -1 & 1 & 715.62 & 85.35 & 46.52 & 77.81 & 927.13 & 165.68 & 22.03 \\
\hline F13 & -1 & -1 & 1 & 1 & 665.45 & 193.96 & 43.25 & 233.42 & 776.78 & 154.45 & 19.86 \\
\hline F14 & 1 & -1 & 1 & 1 & 715.62 & 85.35 & 46.52 & 233.42 & 776.78 & 167.72 & 18.64 \\
\hline F15 & -1 & 1 & 1 & 1 & 665.45 & 193.96 & 43.25 & 233.42 & 776.78 & 152.28 & 23.47 \\
\hline F16 & 1 & 1 & 1 & 1 & 715.62 & 85.35 & 46.52 & 233.42 & 776.78 & 165.68 & 22.03 \\
\hline CC1 & -2 & 0 & 0 & 0 & 639.26 & 375.27 & 28.77 & 155.61 & 851.96 & 144.79 & 25.04 \\
\hline CC2 & 2 & 0 & 0 & 0 & 739.65 & 177.48 & 33.28 & 155.61 & 851.96 & 171.23 & 22.81 \\
\hline CC3 & 0 & -2 & 0 & 0 & 690.90 & 273.54 & 31.09 & 155.61 & 851.96 & 160.78 & 19.91 \\
\hline CC4 & 0 & 2 & 0 & 0 & 690.90 & 273.54 & 31.09 & 155.61 & 851.96 & 156.00 & 27.87 \\
\hline CC5 & 0 & 0 & -2 & 0 & 690.90 & 273.54 & 31.09 & 0.00 & 1002.30 & 158.39 & 23.89 \\
\hline CC6 & 0 & 0 & 2 & 0 & 690.90 & 273.54 & 31.09 & 311.22 & 701.61 & 158.39 & 23.89 \\
\hline CC7 & 0 & 0 & 0 & -2 & 690.90 & 542.86 & 3.45 & 155.61 & 851.96 & 154.91 & 29.69 \\
\hline CC8 & 0 & 0 & 0 & 2 & 690.90 & 4.22 & 58.73 & 155.61 & 851.96 & 161.87 & 18.09 \\
\hline Mini & & & & & 639.3 & 4.2 & 3.5 & 0.0 & 701.6 & 144.8 & 18.1 \\
\hline Maxi & & & & & 739.7 & 542.9 & 58.7 & 311.2 & 1002.3 & 171.2 & 29.7 \\
\hline
\end{tabular}

ranged from 145 to $171 \mathrm{~kg} / \mathrm{m}^{3}$. It should be pointed that the mixing water indicated in Table 3 was corrected to take into account the water present in the superplasticizer and the water absorption of fine sand; nevertheless, more water was added initially to saturate ECat (30\% of ECat weight), as high as $93.4 \mathrm{~kg} / \mathrm{m}^{3}$. A relatively high dosage of $\mathrm{Sp}$ $\left(19-30 \mathrm{~kg} / \mathrm{m}^{3}\right)$ was necessary to obtain mixtures with the improved workability (self-compacting ability). This also facilitated the casting of specimens, particularly the corrugated tubes used to measure autogenous shrinkage.

For each mixture in Table 3, the final spread diameter $\left(Y_{1}\right)$, final setting time $\left(Y_{2}\right)$, autogenous shrinkage $\left(Y_{3}\right)$, resistivity $\left(Y_{4}\right)$ and the 28 days compressive strength $\left(Y_{5}\right)$ were evaluated.

A CCD allows the identification of empirical models by fitting a second-order polynomial equation to the experimental data for each selected response variable $\left(Y_{\mathrm{i}}\right)$. The general form of the second-order model is:

$Y=\beta_{0}+\sum_{i=1}^{k} \beta_{i} X_{i}+\sum_{i=1}^{k} \beta_{i i} X_{i}^{2}+\sum_{i<j} \sum \beta_{i j} X_{i} X_{j}+\varepsilon$

where $Y$ is the predicted response; $X_{i}$ correspond to the design variables; $\beta_{0}, \beta_{i} \beta_{i j}$ are the model parameters and $\varepsilon$ is the error term.

\subsection{Mixing procedure and specimens preparation}

UHPC mixtures (Table 3) were tested in a random order and prepared in batches of 1.40 L, using a mixer in accordance with EN 196-1. The mixing procedure had the following steps: (1) mixing ECat (dry state) with $80 \%$ mixing water plus the water needed for ECat absorption for $5 \mathrm{~min}$; (2) adding sand and remaining powder materials and mixing for $2.5 \mathrm{~min}$; (3) stopping to scrape material adhering to the mixing bowl and mixing for another $2.5 \mathrm{~min}$; (4) introducing the rest of the water plus $75 \%$ of Sp and mixing for $2.5 \mathrm{~min}$; (5) adding the rest of Sp and mixing for $3.5 \mathrm{~min}$. The rotation speed of the mixer was always constant and set equal to $140 \mathrm{rpm}$. The total mixing time was longer than usual because of an additional of $5 \mathrm{~min}$ in step (1), to allow the ECat water absorption. After mixing, all specimens were cast in one lift without any mechanical vibration due to the self-compacting ability of the mixtures. The specimens were then covered with a plastic sheet and demoulded after 1 day. Thereafter, the samples were maintained in water, at $20 \pm 2{ }^{\circ} \mathrm{C}$, until the age of testing.

The aftermost UHPFRC mixtures preparation followed the same mixing procedure - except the fibres incorporation during $2 \mathrm{~min}$ before the end of the mixing process - and conditions of specimens preparation.

\subsection{Test methods}

\subsubsection{Workability and setting time}

Immediately after mixing, the slump-flow diameter was measured using a mini-cone according to EFNARC recommendations. Due to the high content of very fine materials and very low water/binder ratio, UHPC mixtures typically exhibit high viscosity, with low risk of segregation, for this reason, no additional test was carried out to characterize the fresh state. The final setting times were determined in accordance with standard EN 196-3.

\subsubsection{Autogenous shrinkage}

Two samples of each mixture were cast in corrugated plastic tubes and stored at a constant temperature $\left(20 \pm 2{ }^{\circ} \mathrm{C}\right)$ and $50 \pm 2 \% \mathrm{RH}$, immediately after casting. Although the experimental plan was set to have all mixtures with the self-compacting ability in the fresh state, a slight vibration was applied during casting, to guarantee the complete filling of the corrugated tubes. Autogenous shrinkage was measured following the procedure described in the American standard ASTM C1698. Shrinkage measurements were continuously recorded (each minute) using linear variable differential transformers (LVDTs) and a data Taker DT500 acquisition system. The final setting time, previously determined, was considered as "time-zero" for the autogenous shrinkage evaluation [47]. In all mixtures, the autogenous deformation of two tested samples had a similar trend with a deviation of less than $58 \mu \mathrm{m} / \mathrm{m}$. Since the variation in temperature of the thin samples during hydration is small and almost the same among the different mixtures, the effect of the thermal dilatation to the value of autogenous shrinkage 
was not considered. Smoeck et al. [46] carried out similar tests and monitored the internal temperature over time both on specimens placed in a polyakylene-glycol termobath at $20^{\circ} \mathrm{C}$ and on specimens placed in a chamber with controlled temperature $\left(20 \pm 1{ }^{\circ} \mathrm{C}\right)$. The maximum temperature increase in specimens placed in the termobath was only $0.6^{\circ} \mathrm{C}$, while for specimens placed in the chamber a temperature peak of $3.5^{\circ} \mathrm{C}$ was registered. Nevertheless, this additional peak of $3.5^{\circ} \mathrm{C}$ had little influence on the overall results, corresponding to an error approximately $1 \%$, lower than the measuring error of the test.

\subsubsection{Resistivity and compressive strength}

Cubic specimens $(50 \mathrm{~mm})$ were produced to assess the electrical resistivity and compressive strength. As mentioned before, specimens were kept under water in a chamber under controlled temperature $\left(20 \pm 2{ }^{\circ} \mathrm{C}\right)$ and removed just for a few minutes to perform the resistivity test at predefined ages: 7, 14, 21 and 28 days.

The two-electrode method was used to determine the resistivity of the specimens under alternating current (AC). AC measurements are generally preferred since the use of direct current (DC) may induce polarisation of the electrodes [47]. Plain mortar with high moisture contents was found to be frequency-independent for the $1 \mathrm{~Hz}-100 \mathrm{kHz}$ frequency range [48]. The resistivity was measured with two stainless steel plates pressed to opposing (mould) surfaces via wetted cloth. A signal generator applied a sinusoidal current of $100 \mathrm{~Hz}$ frequency, and the resistivity ( $\rho$ ) was computed from equation (2), as follows,

$\rho=\frac{V . A}{L . I}(\Omega . \mathrm{m})$

where $V$ is the potential difference (volt); $I$ is the current intensity (amp); $L$ is the distance between electrodes (m); and $A$ is the area of the electrode in contact with the mortar sample $\left(\mathrm{m}^{2}\right)$. At each age three specimens were tested and the corresponding average was taken as the test result.

At the age of 28 days, subsequently to the resistivity measurements, the compressive strength was evaluated according to ASTM C109/ C109 M. Three samples from each mixture were tested.

\subsubsection{Uniaxial tensile test}

The uniaxial tensile test (UTT) was only performed in UHPFRC mixtures using dog bone-shaped specimens with tested section length of $92 \mathrm{~mm}$ and cross section of $30 \times 40 \mathrm{~mm}^{2}$, after 28 curing days in a controlled environment room (temperature $=20 \pm 2{ }^{\circ} \mathrm{C}$ and HR $>95 \%$ ). Six specimens were tested at a displacement rate of $0.003 \mathrm{~mm} / \mathrm{s}$ applied by an Instron testing machine with a $300 \mathrm{kN}$ capacity load cell. This displacement rate was kept constant until the end of the test. The elongation of the specimens was measured using four LVDT's system coupled along the tested section length of the specimen (see Fig. 3b).

\section{Results}

\subsection{Test results}

\subsubsection{Workability and final setting time}

Table 4 (second and third columns) presents the results of slump flow diameter (Dflow) and final setting time (tf) for all the mixtures included in the experimental plan. Regarding the fresh state behaviour, all mixtures exhibited self-compacting ability, with slump flow diameters ranging from 229 to $350 \mathrm{~mm}$. The final setting times ranged from 1.42 to $3.75 \mathrm{~h}$. An extensive range of setting time results for UHPC can be found in the literature $[1,49]$ since it varies significantly with the type and amount of superplasticizer and type of cementitious materials used. A general tendency of longer final setting times with increasing flowability was observed in the current study (see Fig. 4).

\subsubsection{Autogenous shrinkage}

Fig. 5 shows the autogenous shrinkage evolution of all mixtures up to $20 \mathrm{~h}$ (after final setting time). Even though a wide range of deformations was found $(494-1011 \mu \mathrm{m} / \mathrm{m})$, the evolution over time presents a similar trend. During the first hours from the final setting, autogenous shrinkage exhibited a strong increase, after which a dramatic reduction in the slope of the curves was observed. Wang et al. [19] also reported the autogenous shrinkage of plain UHPC increases fast in the early stage, and almost keep stable after $24 \mathrm{~h}$, reaching $1175 \mu \mathrm{m} / \mathrm{m}$ at 7 days. Nevertheless, it is worth pointing that results of autogenous shrinkage depend on the method used to define "time-zero", as highlighted by Huang and Ye [49]. Results of autogenous shrinkage deformation at $20 \mathrm{~h}$ (a_shr_20 h) after the final setting time were used in modelling and are presented in the fourth column of Table 4.

\subsubsection{Electrical resistivity}

Fig. 6 presents the electrical resistivity development up to 28 days. As expected, the electrical resistivity of tested mixtures increased with age due to continued hydration, leading to finer pore network with less connectivity. Resistivity results at 28 days ranged from 147 to $474 \Omega \mathrm{m}$, which indicates a very compact matrix. As a reference, after 10 years a dense-aggregate concrete incorporating $>5 \%$ silica fume, submerged at $20^{\circ} \mathrm{C}$, is expected to exhibit a resistivity from 300 to $1000 \Omega \mathrm{m}$ [47]. Mix CC5 (without incorporation of ECat) exhibited the highest gain in resistivity achieving 121, 192 and $474 \Omega \mathrm{m}$ after 7, 14 and 28 days, respectively. Fig. 6 also suggests that resistivity of all mixtures will continue to increase further beyond the 28 days. The 5 th column in Table 4 includes the resistivity at 28 days data used for modelling.

\subsubsection{Compressive strength}

The last column of Table 4 lists the 28-day compressive strength (Rc_28d) test results. The compressive strength of tested mixtures achieved a minimum of $103 \mathrm{MPa}$ and a maximum of $143 \mathrm{MPa}$ at 28 days, without any special curing treatment. Due to the absence of fibres a brittle failure was observed, which is responsible for a higher scatter in the compressive strength results of each mixture. Moreover, the summary of descriptive statistics in Table 5 reveals that both the
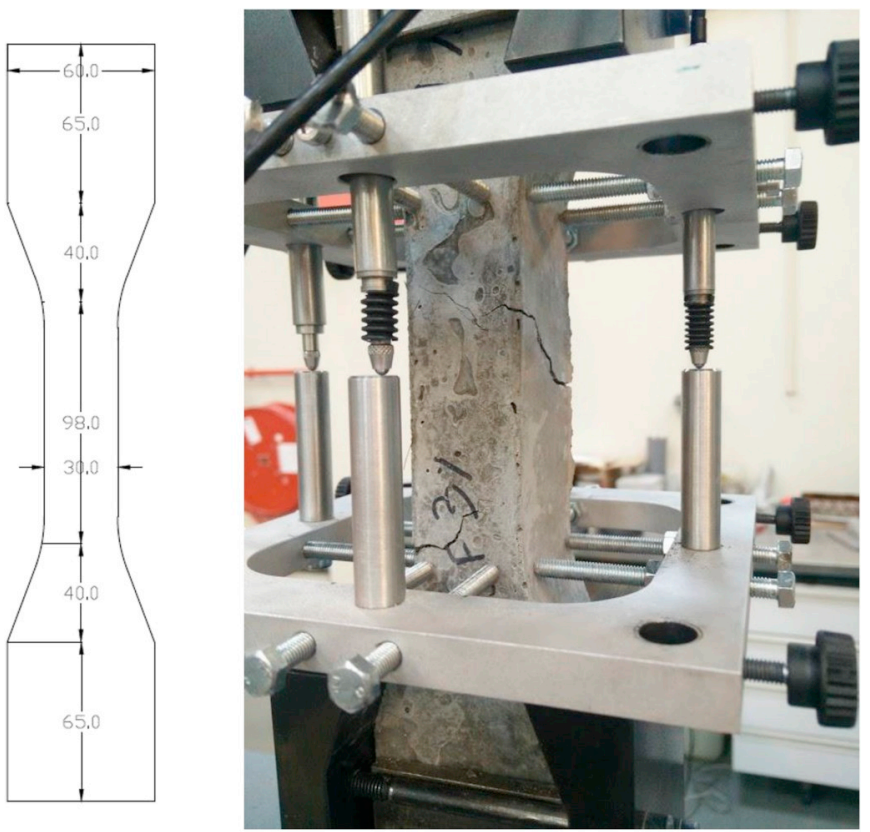

a)

b)

Fig. 3. Uniaxial tensile test setup: (a) Specimens geometry (mm); (b) LVDTs arrangement. 
Table 4

Test results for all mixtures included in the CCD experimental plan.

\begin{tabular}{|c|c|c|c|c|c|}
\hline Ref. & $\begin{array}{l}\text { Dflow } \\
(\mathrm{mm})\end{array}$ & $\begin{array}{l}\text { tf } \\
\text { (h) }\end{array}$ & $\begin{array}{l}\text { a_shr_20h } \\
(\mu \mathrm{m} / \mathrm{m})\end{array}$ & $\begin{array}{l}\rho \_28 \mathrm{~d} \\
(\Omega \mathrm{m})\end{array}$ & $\begin{array}{l}\text { Rc_28d } \\
(\mathrm{MPa})\end{array}$ \\
\hline $\mathrm{C} 1$ & 292.5 & 2.77 & 725.1 & 231.2 & 107.4 \\
\hline $\mathrm{C} 2$ & 288.0 & 2.43 & 777.2 & 247.2 & 127.5 \\
\hline C3 & 292.0 & 2.33 & 685.1 & 225.5 & 133.4 \\
\hline $\mathrm{C} 4$ & 297.5 & 2.27 & 708.9 & 206.2 & 118.3 \\
\hline C5 & 300.0 & 2.62 & 718.8 & 229.2 & 123.4 \\
\hline C6 & 300.0 & 2.58 & 674.1 & 215.1 & 125.2 \\
\hline $\mathrm{F} 1$ & 233.0 & 1.83 & 747.9 & 241.7 & 124.4 \\
\hline F2 & 288.5 & 2.58 & 791.3 & 221.9 & 116.1 \\
\hline F3 & 255.0 & 2.68 & 716.5 & 279.2 & 114.8 \\
\hline F4 & 282.0 & 3.33 & 709.1 & 237.5 & 114.0 \\
\hline F5 & 230.0 & 1.53 & 523.3 & 175.0 & 113.4 \\
\hline F6 & 287.5 & 2.27 & 555.5 & 168.5 & 116.1 \\
\hline F7 & 241.0 & 1.67 & 519.9 & 188.1 & 110.6 \\
\hline F8 & 264.0 & 2.42 & 512.1 & 178.6 & 115.1 \\
\hline F9 & 287.8 & 2.67 & 818.9 & 339.2 & 132.1 \\
\hline F10 & 350.0 & 2.75 & 1011.2 & 305.0 & 143.1 \\
\hline F11 & 287.5 & 2.65 & 829.2 & 341.8 & 135.0 \\
\hline F12 & 325.0 & 3.75 & 844.7 & 284.7 & 124.7 \\
\hline $\mathrm{F} 13$ & 267.5 & 1.67 & 667.2 & 176.5 & 118.0 \\
\hline F14 & 328.5 & 1.83 & 746.8 & 150.0 & 123.5 \\
\hline F15 & 277.5 & 2.17 & 609.0 & 187.4 & 107.9 \\
\hline F16 & 302.0 & 2.75 & 708.6 & 156.2 & 119.9 \\
\hline CC1 & 255.0 & 1.95 & 719.7 & 246.2 & 102.9 \\
\hline CC2 & 326.0 & 2.78 & 823.9 & 195.6 & 140.3 \\
\hline CC3 & 300.0 & 1.75 & 701.8 & 201.1 & 106.6 \\
\hline CC4 & 282.5 & 3.00 & 712.4 & 204.8 & 110.0 \\
\hline CC5 & 305.0 & 3.18 & 825.9 & 474.2 & 129.3 \\
\hline CC6 & 289.0 & 1.42 & 645.0 & 146.7 & 112.6 \\
\hline CC7 & 228.5 & 1.80 & 497.5 & 191.0 & 111.2 \\
\hline CC8 & 310.0 & 2.67 & 794.0 & 185.1 & 126.1 \\
\hline
\end{tabular}

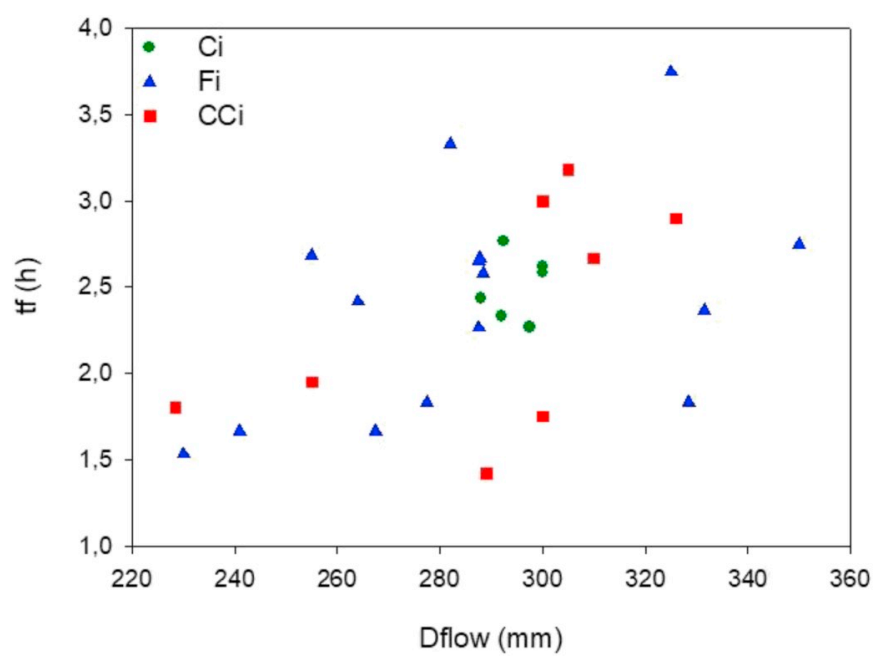

Fig. 4. Slump flow diameter and final setting time test results.

average and the coefficient of variation of compressive strength results found for central mixtures and for all the mixtures are very close, which can be a consequence of the constant $\mathrm{w} / \mathrm{c}$ ratio and relatively small range of variation of reactive materials other than cement (SF and ECat). This indicates it will not be possible to find a good fit for the Rc_28d response model, as confirmed in the next section. Contrarily, for all the other response variables the coefficient of variation evaluated on the central points is significantly smaller than the coefficient of variation evaluated on the 30 mixtures, thus good fitting models could be expected.

\subsection{Fitted models}

The procedure to find an appropriate model establishing relationships between mix design variables and the responses involves two main steps:

1. Fitting a second-order polynomial model using regression analysis and ANOVA, including the removal of non-significant terms in the model (p-value $>0.05$ ).

2. Model adequacy checking by examining the residuals, looking for trends and/or outliers.

A detailed description of this procedure can be found in a previous publication by the authors [39] and/or in specialized bibliography [37].

Table 6 summarizes the fitted models with the design variables expressed in coded values, along with the residual error standard deviation and the correlation coefficients. An inverse transformation was applied to $\rho_{-} 28 \mathrm{~d}$ response data in order to stabilize the response variance and improve the resulting model [37]. ANOVA showed that these models are significant when describing the effect of $V_{w} / V_{p}, S p / p, V_{E C a t} / V_{s}$ and $s f / c$ on the modelled responses. From the results of $\mathrm{R}^{2} / \mathrm{Adj}-\mathrm{R}^{2}$ in Table 6 , it can be concluded that the obtained regression models explain a large proportion of the variability of the analysed properties, except in the case of $R c$-28d response (Adj- $R^{2}=47 \%$ ), because of the reasons pointed before in section 3.1.

\subsection{Main individual and interaction effects}

The models presented in Table 6 reflect the relative significance of each term on the response variables.

The Dflow of UHPC was mainly influenced by the $s f / c$ and $V_{w} / V_{p}$. The positive influence of $s f / c$ on the flowability may be attributed to the increased packing density due to the inclusion of extremely small spherical silica fume particles [50]. For a given water content, when packing density increases more free water is available in the system which leads to improved flowability. An increase of $V_{w} / V_{p}$ corresponds to an increase in the water content, thus a thicker water layer is formed around the solid particles which explains the larger slump flow diameter [50]. The slightly negative effect of $V_{E C a t} / V_{s}$ on flowability might be attributed to the not fully water saturation of ECat particles reached during the initial time ( $5 \mathrm{~min}$ ) of the UHPC mixture procedure.

The final setting time of UHPC was mainly influenced by $V_{w} / V_{p}, S p / p$ and $V_{E C a t} / V_{s}$. As expected, an increase of water content or superplasticizer dosage, particularly for relatively high dosages, retards the final setting $[28,39]$. Also, previous studies revealed that ECat incorporation in cement-based materials led to shorten the setting time due to its highly porous microstructure that provides a large specific surface area $\left(150070 \mathrm{~m}^{2} / \mathrm{Kg}\right.$ for the ECat under study, section 2.1) with high water absorption ability (30\%, section 2.1$)$ [28,33].

Autogenous shrinkage had a major influence of $s f / c$. As reported in previous studies [13], autogenous shrinkage increases with increasing SF content, which causes a significant drop in the internal $\mathrm{RH}$ in the cement paste during the hardening leading to the occurrence of selfdesiccation in the absence of an external source of water. An opposing significant effect was found for $V_{E C a t} / V_{s}$, which proves a remarkable beneficial effect to mitigate autogenous shrinkage of UHPC. This effect is attributed to the absorbed water in the porous ECat particles that can be released during the first day of hydration to compensate the drop of RH in UHPC. This result supports the idea that ECat can act as an internal curing agent to mitigate the high autogenous shrinkage of UHPC. The abovementioned opposite effects of $s f / c$ and $V_{E C a t} / V_{s}$ on autogenous shrinkage can be observed in Fig. 7 (corresponding to mixtures with $\mathrm{Sp}$ / $\mathrm{p}$ and $\mathrm{Vw} / \mathrm{Vp}$ set fixed at $2.40 \%$ and 0.395 , respectively).

Both, resistivity and compressive strength properties at $28 \mathrm{~d}$ are negatively affected by the ECat incorporation as sand partial surrogate, and positively affected by $s f / c$. This effect of ECat incorporation on these properties was the opposite of the anticipated given the high pozzolanic activity of ECat that promote the formation of additional 


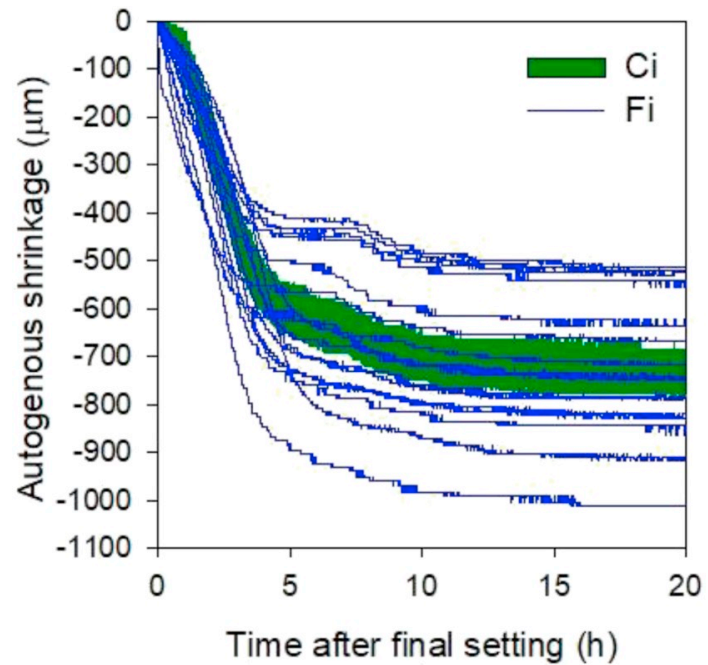

(a)

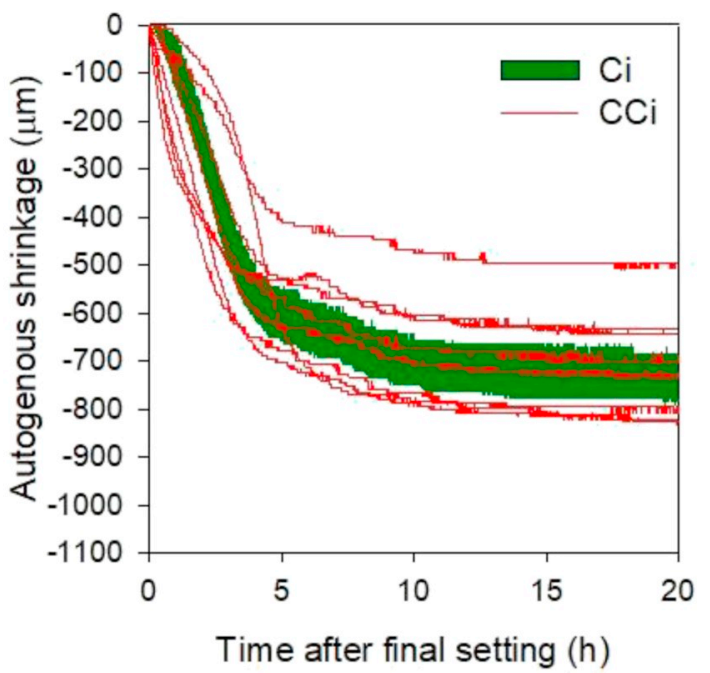

(b)

Fig. 5. Autogenous shrinkage evolution of mixtures included in Table 3: mixtures Fi (a), mixtures CCi (b), and range of results obtained with Ci mixtures.

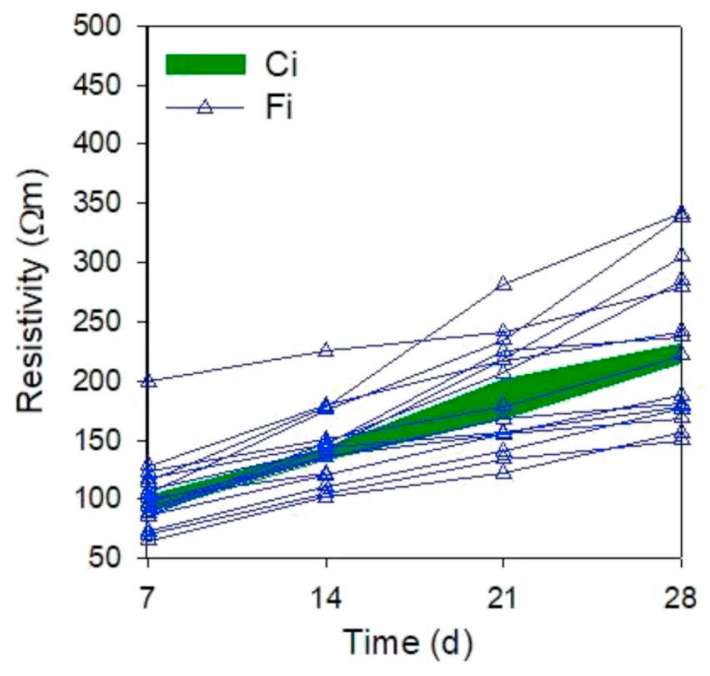

(a)

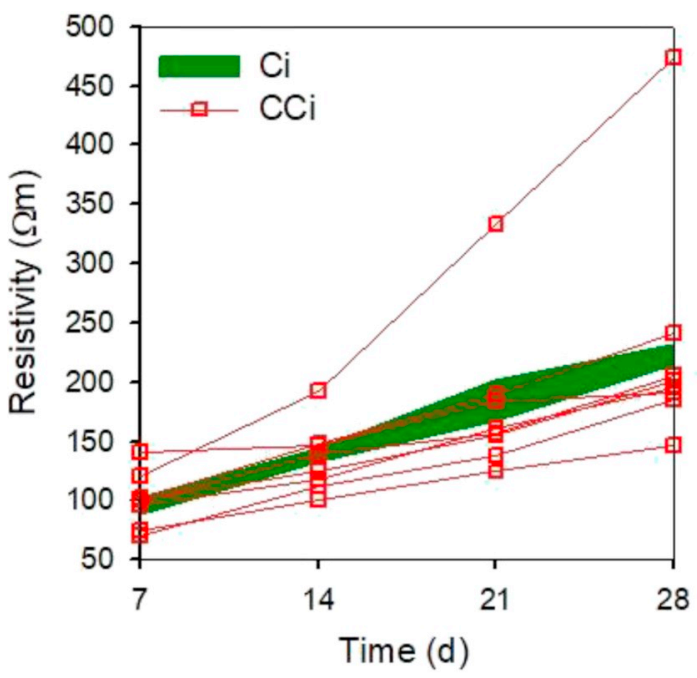

(b)

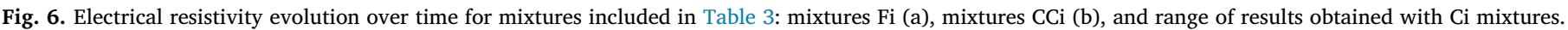

Table 5

Descriptive statistics of the results for all 30 mixtures as well as only for the 6 central mixtures.

\begin{tabular}{|c|c|c|c|c|c|}
\hline & $\begin{array}{l}\text { Dflow } \\
(\mathrm{mm})\end{array}$ & $\begin{array}{l}\mathrm{tf} \\
(\mathrm{h})\end{array}$ & $\begin{array}{l}\text { a_shr_20h } \\
(\mu \mathrm{m} / \mathrm{mm})\end{array}$ & $\begin{array}{l}\rho \_28 d \\
(\Omega \mathrm{m})\end{array}$ & $\begin{array}{l}\text { Rc_28d } \\
(\mathrm{MPa})\end{array}$ \\
\hline \multicolumn{6}{|l|}{ All 30 mixtures } \\
\hline Mean & 285.76 & 2.40 & 710.68 & 227.69 & 120.09 \\
\hline Minimum & 228.50 & 1.42 & 497.47 & 146.73 & 102.87 \\
\hline Maximum & 350.00 & 3.75 & 1011.16 & 474.25 & 143.08 \\
\hline Std deviation & 29.46 & 0.56 & 114.49 & 68.84 & 10.23 \\
\hline Coef. Var (\%) & 10.3 & 23.3 & 16.1 & 30.2 & 8.5 \\
\hline \multicolumn{6}{|c|}{6 central mixtures } \\
\hline Mean & 295.00 & 2.50 & 714.86 & 225.74 & 122.54 \\
\hline Minimum & 288.00 & 2.27 & 674.12 & 206.17 & 107.39 \\
\hline Maximum & 300.00 & 2.77 & 777.21 & 247.23 & 133.39 \\
\hline Std deviation & 4.91 & 0.19 & 36.30 & 14.14 & 8.92 \\
\hline Coef. Var (\%) & 1.7 & 7.6 & 5.1 & 6.3 & 7.3 \\
\hline
\end{tabular}

hydration products and, thus, the refinement of capillary porosity and the decrease of the porous interconnectivity in the cement matrix. The increasing of resistivity and compressive strength with ECat
Table 6

Empirical fitted models (design variables in coded values).

\begin{tabular}{|c|c|c|c|c|c|}
\hline Model terms & $\begin{array}{l}\text { Dflow } \\
(\mathrm{mm})\end{array}$ & $\begin{array}{l}\text { tf } \\
(\mathrm{h})\end{array}$ & $\begin{array}{l}\text { a_Shr_20h } \\
(\mu \mathrm{m} / \mathrm{m})\end{array}$ & $\begin{array}{l}1 /\left(\rho_{-} 28 \mathrm{~d}\right) \\
(\Omega \mathrm{m})\end{array}$ & $\begin{array}{l}\text { Rc_28d } \\
(\mathrm{MPa})\end{array}$ \\
\hline Independent & 291.24 & 2.407 & 726.78 & 4.454E-3 & 122.50 \\
\hline $\mathrm{Vw} / \mathrm{Vp}$ & 20.42 & 0.270 & 27.33 & $2.746 \mathrm{E}-4$ & 3.08 \\
\hline $\mathrm{Sp} / \mathrm{p}$ & -3.08 & 0.283 & NS & $-8.958 \mathrm{E}-5$ & -1.57 \\
\hline $\mathrm{V}_{\mathrm{ECat}} / \mathrm{V}_{\mathrm{s}}$ & -5.95 & -0.395 & -82.84 & $+1.123 \mathrm{E}-3$ & -4.72 \\
\hline $\mathrm{sf} / \mathrm{c}$ & $\underline{21.16}$ & $\overline{0.152}$ & $\overline{73.04}$ & $\overline{-8.068 \mathrm{E}-5}$ & $\overline{4.56}$ \\
\hline$(\mathrm{Vw} / \mathrm{Vp}) \times(\mathrm{Sp} / \mathrm{p})$ & -7.76 & NS & NS & NS & NS \\
\hline$\left(\mathrm{V}_{\mathrm{ECat}} / \mathrm{V}_{\mathrm{s}}\right) \times(\mathrm{sf} / \mathrm{c})$ & NS & NS & NS & $+3.293 \mathrm{E}-4$ & NS \\
\hline$(\mathrm{Sp} / \mathrm{p})^{2}$ & NS & NS & NS & $+1.044 \mathrm{E}-4$ & -3.04 \\
\hline$(\mathrm{sf} / \mathrm{c})^{2}$ & -6.86 & NS & -20.12 & $+2.023 \mathrm{E}-4$ & NS \\
\hline \multicolumn{6}{|l|}{ Error term } \\
\hline Mean & 0.00 & -0.01 & 0.00 & 0.01 & 0.00 \\
\hline Std. Dev. & 1.04 & 1.02 & 1.04 & 1.03 & 1.00 \\
\hline $\mathrm{R}^{2}$ & $96.0 \%$ & $87.5 \%$ & $84.8 \%$ & $96.6 \%$ & $56.1 \%$ \\
\hline Adj- $R^{2}$ & $94.9 \%$ & $85.5 \%$ & $82.3 \%$ & $95.5 \%$ & $47.0 \%$ \\
\hline
\end{tabular}

NS: non-significant term. The three most significant parameters, for each response variable, are typed bold, and the most significant term is also underlined. 


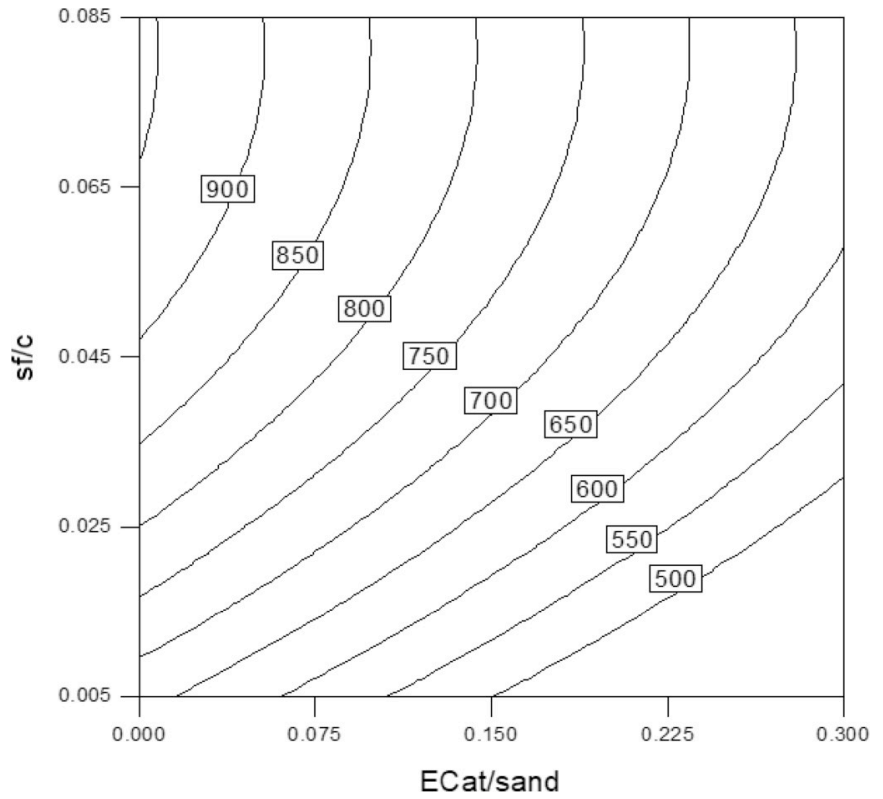

Fig. 7. Contour plot of autogenous shrinkage $(\mu \mathrm{m} / \mathrm{m})(S p / p=2.40 \%$ and $\left.V_{w} / V_{p}=0.395\right)$.

incorporation was found in previous studies [26,28,51]. However, in the present study, UHPC mixtures incorporated two very highly reactive pozzolanic materials, SF and ECat, both simultaneously competing for the calcium hydroxide that presumably is not enough to complete both reactions. As such, a negative synergistic effect might had occurred that lead to the decrease on the resistivity and compressive strength, at 28 days, as the ECat content increased.

The interaction effect $\left(V_{E C a t} / V_{s} \times s f / c\right)$ was also found to be significant to explain the resistivity at 28 days, which is graphically represented in Fig. 8. This figure shows that the decrease in resistivity with an increase of ECat/sand is stronger for higher values of sf/c. Table 6 also shows that the resistivity at 28 days decreases with an increase of $V_{w} / V_{p}$, since by increasing the water content the total porosity and pores connectivity increase, thus lowering the resistivity.

\subsection{Mixtures optimisation}

The optimisation of UHPC mixtures was performed using the response surface of the models presented in Table 6 as the basis for finding the best solution. Numerical optimisation was performed based on the desirability function approach available in the commercial software (Design-Expert) [44].

Table 7 shows the four different optimisation scenarios implemented and the corresponding UPHC mixtures composition. In brief, in scenarios A and B the main objective is to minimize autogenous shrinkage; in scenario $C$ the main objective is to maximize resistivity as an indicator of material durability; and finally, scenario D aimed to obtain the best solution possible in order to simultaneously minimize shrinkage and maximize resistivity (both constraints having equal importance). After finding a candidate solution for the optimisation problem, attention must also be paid to the distance to the centre of the CCD plan (d), computed as indicated in the last line of Table 7. The distance to the centre of the CCD plan should not exceed 2 by far (region of the original data), because the fitted models may no longer predict in a reasonable way outside of the CCD region.

In general, the design variables (coded values) were always set to be in the range of $[-2,+2]$, except when the final optimized solution was very far from the centre of the experimental plan, as was the case of Mixture A (optimal solution Scenario A) for which $d=3.35$. To avoid this situation the range of design variables $V_{w} / V_{p}, S p / p$, and $V_{E C a t} / V_{s}$ was limited in some cases as shown in Table 7. Concerning the response variables, the reasoning behind the selected constraints (Table 7) was the following:

- For all scenarios, the target minimum slump flow diameter of UHPC was $300 \mathrm{~mm}$, considering that after fibres incorporation (3\% content) some deformability loss can be expected [52].

- In scenarios A, B and D autogenous shrinkage was minimized aiming to reduce the early-ages cracking risk.

- In scenarios C and D resistivity was maximized looking for to improve the resistance against the penetration of liquid or gas substances.

Since the observed variation in the compressive strength for all the tested mixtures was not very significant $(8.5 \%)$, and close to the experimental error (7.3\%), it was not possible to distinguish the mixtures regarding the compressive strength. Thus, no constraint was added related to this response variable.

Table 7 presents the optimum solutions (in terms of coded values). As could be expected from the discussion in the previous section, scenario A led to a mixture with the highest $V_{E C a t} / V_{s}$ and the lowest $s f / c$. In contrast to scenario $\mathrm{C}$ led to low $V_{E C a t} / V_{s}$ and relatively high $s f / c$. In turn, the mixture resulting from scenario $\mathrm{D}$ represents the best compromise between low autogenous shrinkage, at early ages, and high resistivity at 28 days. Concerning the distances to the centre of the experimental plan of mixtures $A$ to $D$, one can note that $d_{\mathrm{A}}>d_{\mathrm{B}}>d_{\mathrm{C}}>d_{\mathrm{D}}$ with $d_{\mathrm{A}}$ and $d_{\mathrm{B}}$ being higher than 2.5.

\subsection{Optimized mixtures validation}

In order to validate the numerical models obtained (Table 6), the optimized mixtures (A to D) and an additional central mixture (C7) were prepared in the laboratory and tested following the procedures described in sections 2.3 and 2.4. Table 8 shows both the experimental (measured) and predicted results. Uncertainty in the fitted models is provided for a $95 \%$ confidence interval. The ratio between the predicted-to-measured values in general range from 0.8 to 1.11 , which confirms the accuracy of the obtained models. The exceptions are Mixtures A and B, corresponding to the highest distances to the centre of the CCD plan, which confirms the adequacy of the limit of 2.5 for $d$, in these type of CCD experimental plans. The experimental compressive strength results of UHPC optimized mixtures, assessed at 90 days, are presented in Table 8. In this case, no comparison with the predicted values can be established since it was not possible to model the Rc_28d response variable (as discussed in Section 3.2).

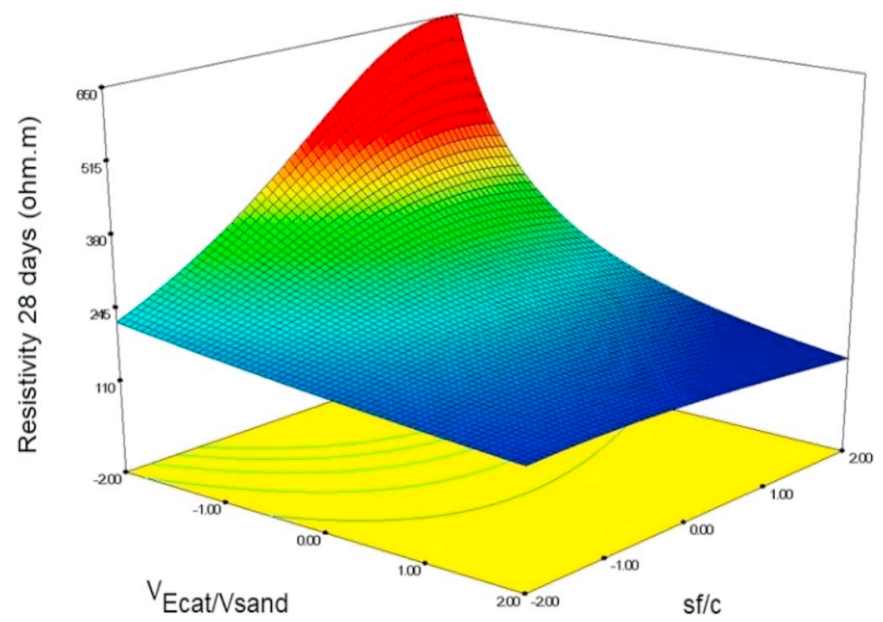

Fig. 8. Interaction effect of $V_{E C a t} / V_{s}$ and $s f / c$ on resistivity at $28 \mathrm{~d}(S p / p=0$ and $V_{w} / V_{p}=0$, in coded values). 
Table 7

Optimisation criteria and optimum solutions (design variables in coded values).

\begin{tabular}{|c|c|c|c|c|}
\hline & Scenario A & Scenario B & Scenario C & Scenario D \\
\hline \multicolumn{5}{|l|}{ Optimisation constraints: } \\
\hline$X_{1}: \mathrm{Vw} / \mathrm{Vp}$ & In range* & In range $[-1.50 ; 1.50]$ & In range* & In range * \\
\hline$X_{2}: \mathrm{Sp} / \mathrm{p}$ & In range * & In range $[-1.50 ; 1.50]$ & In range* & In range* \\
\hline$X_{3}:$ VEcat/Vs & In range * & In range $[-1.63 ; 1.51]$ & In range* & In range $[-1.60 ; 1.25]$ \\
\hline$X_{4}: \mathrm{sf} / \mathrm{c}$ & In range* & In range* & In range * & In range * \\
\hline Y1: Dflow (mm) & In range $[300 ; 350]$ & Maximize & In range $[300 ; 350]$ & In range $[300 ; 350]$ \\
\hline Y2: tf (h) & None & None & None & None \\
\hline Y3: Aut_Shr $(\mu \mathrm{m} / \mathrm{mm})$ & Minimize & Minimize & None & Minimize \\
\hline Y4: $\rho \_28 \mathrm{~d}(\Omega \mathrm{m})$ & None & None & Maximize & Maximize \\
\hline Optimum solution: & Mixture A & Mixture B & Mixture C & Mixture D \\
\hline$X_{1}: \mathrm{Vw} / \mathrm{Vp}$ & 1.80 & 1.50 & -0.65 & -0.05 \\
\hline$X_{2}: \mathrm{Sp} / \mathrm{p}$ & -1.70 & -1.50 & -0.16 & -2.00 \\
\hline$X_{3}: V_{E C a t} / V_{S}$ & 1.76 & 1.51 & -2.00 & 0.00 \\
\hline$X_{4}: \mathrm{sf} / \mathrm{c}$ & -1.40 & 0.00 & 1.40 & 0.20 \\
\hline$d=\sqrt{\sum_{i=1}^{4} X_{i}^{2}}$ & 3.35 & 2.60 & 2.52 & 2.00 \\
\hline
\end{tabular}

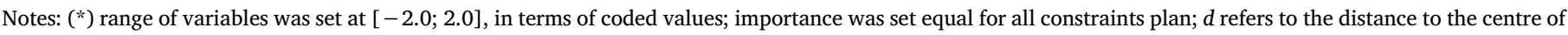
the experimental.

Considering the main goal of the current work of mitigating UHPC autogenous shrinkage, it is worth pointing that mixture D exhibited an autogenous shrinkage about $32 \%$ lower than the highest result found in the experimental plan of $1011 \mu \mathrm{m} / \mathrm{m}$ (corresponding to mixture F10, see Table 4), due to the significant amount of water absorbed by ECat. $V_{E C a t} / V_{s}$ ratio in mixture $\mathrm{D}$ is zero, expressed in coded values, i.e 0.15 in actual values, corresponding to about $155 \mathrm{~kg} / \mathrm{m}^{3}$ of ECat and theoretically to about $46.61 / \mathrm{m}^{3}$ of total absorbed water by the ECat (Section 2.1). This is within the range of extra water absorbed for internal curing of UHPC by other materials such as, SAPs (33-56 $/ \mathrm{m}^{3}$ ) [17] and LWS $\left(11-631 / \mathrm{m}^{3}\right)$ [15] and is higher than the total water absorbed by $220 \mathrm{~kg} / \mathrm{m}^{3}$ of RHA (about $18.91 / \mathrm{m}^{3}$ ) [9].

\section{Performance of fibre reinforced composite}

UHPC exhibits a distinctly brittle failure under tension, but provided it is reinforced with a sufficiently high fibre content, using short highstrength steel fibres, the tensile strength of UHPC can be improved and ensured to such an extent [14] that UHPFRC can be applied in thin layers to protect/strengthen existing structures, without any further reinforcement [35]. The fibre orientation has a large influence on the tensile response of UHPFRC, most notably in the development of the hardening stage, and a fibre content as high as $3 \%$ is often necessary to achieve a strain hardening behaviour in tension with a random fibre distribution [14].

The optimized UHPC mixture D was selected for further investigation of its performance as UHPFRC. For this purpose, $3 \%$ of micro steel fibres were incorporated in the UHPC mixture by replacing an equivalent volume of aggregates (fine sand plus ECat, maintaining $V_{E C a t} / V_{s}$ ratio) (see Table 9) and tested regarding its flowability, autogenous shrinkage evolution, mechanical performance, cost and environmental impact/eco-efficiency.

\subsection{Flowability}

UHPFRC mixture presented in Table 9 exhibited a slump flow diameter of $282.5 \mathrm{~mm}$, without application of compaction energy (Fig. 9) and revealed no fibre agglomeration. As such, the Dflow of the UHPFRC mixture prepared from the optimized UHPC mixture D with the incorporation of $3 \%$ fibres showed a Dflow of $9.4 \%$ smaller than that of mixture D (Table 8). This is in agreement with the findings of Marchão et al. [52], which concluded that the addition of fibres with a fibre factor, $\chi=V_{f} \times l_{f} / d_{f}$, in between 1 and 2, like in the current study with $\chi=1.95\left(\mathrm{~V}_{\mathrm{f}}=3 \%\right.$ and $\left.\mathrm{l}_{\mathrm{f}} / \mathrm{d}_{\mathrm{f}}=65\right)$, results only in a slight and linear decrease of Dflow with increase of $\chi$, without fibre agglomeration.

Table 8

Experimental and predicted engineering properties of optimum mixtures.

\begin{tabular}{|c|c|c|c|c|c|c|}
\hline & & Mixture A & Mixture B & Mixture C & Mixture D & C7 \\
\hline \multirow[t]{4}{*}{ Dflow (mm) } & measured & 270 & 312 & 312 & 312 & 300 \\
\hline & predicted & 303 & 335 & 306 & 300 & 291 \\
\hline & prediction interval & {$[283 ; 323]$} & {$[317 ; 353]$} & {$[290 ; 322]$} & {$[284 ; 314]$} & {$[277 ; 305]$} \\
\hline & predicted/measured & 1.12 & 1.07 & 0.98 & 0.96 & 0.97 \\
\hline \multirow[t]{4}{*}{$\mathrm{tf}(\mathrm{h})$} & measured & 1.48 & 1.87 & 3.19 & 2.33 & 2.33 \\
\hline & predicted & 1.50 & 1.81 & 3.18 & 1.86 & 2.40 \\
\hline & prediction interval & {$[0.99 ; 2.06]$} & {$[1.31 ; 2.31]$} & {$[2.69 ; 3.69]$} & {$[1.37 ; 2.34]$} & {$[1.95 ; 2.85]$} \\
\hline & predicted/measured & 1.01 & 0.97 & 1.00 & 0.80 & 1.03 \\
\hline \multirow[t]{4}{*}{ a_shr $(\mu \mathrm{m} / \mathrm{mm})$} & measured & 649 & 753 & 953 & 689 & 699 \\
\hline & predicted value & 488 & 642 & 938 & 739 & 727 \\
\hline & prediction interval & {$[370 ; 606]$} & {$[532 ; 753]$} & {$[820 ; 1052]$} & {$[637 ; 841]$} & {$[625 ; 829]$} \\
\hline & predicted/measured & 0.75 & 0.85 & 0.98 & 1.07 & 1.04 \\
\hline \multirow[t]{4}{*}{$\rho \_28 d(\Omega m)$} & measured & 242 & 214 & 642 & 221 & 251 \\
\hline & predicted & 141 & 144 & 710 & 199 & 225 \\
\hline & prediction interval & {$[128 ; 157]$} & {$[139 ; 158]$} & {$[480 ; 1363]$} & {$[177 ; 227]$} & {$[201 ; 254]$} \\
\hline & predicted/measured & 0.58 & 0.67 & 1.11 & 0.90 & 0.90 \\
\hline Rc_90d (MPa) & measured & $108.24 \pm 5.28$ & $132.36 \pm 0.35$ & $130.80 \pm 2.82$ & $135.80 \pm 2.17$ & - \\
\hline
\end{tabular}

Note: prediction interval with a $95 \%$ confidence level. 
Table 9

Mixture design of fibre reinforced UHPC using selected mixture D, estimated cost and Global Warming Potential (GWP).

\begin{tabular}{|c|c|c|c|c|}
\hline Materials & Quantity $\left(\mathrm{kg} / \mathrm{m}^{3}\right)$ & $\begin{array}{l}\text { Cost }( \\
\left.€ / \mathrm{m}^{3}\right)\end{array}$ & GWP $\left(\mathrm{kg} \mathrm{CO}{ }_{2}\right.$-eq/kg) & $\begin{array}{l}\mathrm{GWP} \\
\times 10^{3}\left(\mathrm{~kg} \mathrm{CO} \mathrm{CO}_{2}-\mathrm{eq} / \mathrm{m}^{3}\right)\end{array}$ \\
\hline Cement & 690.2 & $62.1(11 \%)$ & $0.8330[55]$ & $574.93(45.9 \%)$ \\
\hline Silica fume & 33.6 & $38.6(7 \%)$ & $0.7900[56]$ & $26.51(2.1 \%)$ \\
\hline Limestone filler & 250.6 & $7.5(1 \%)$ & $0.0712[57]$ & $4.31(0.3 \%)$ \\
\hline ECat & 155.5 & $4.7 *(1 \%)$ & $0[58]$ & 0.00 \\
\hline Sand & 775.0 & $11.6(2 \%)$ & $0.0011[57]$ & $0.82(0.1 \%)$ \\
\hline Superplasticizer & 19.5 & $24.4(4 \%)$ & $0.9440[57]$ & $18.40(1.5 \%)$ \\
\hline Steel fibres & 235.0 & $423(74 \%)$ & $2.6700[55]$ & $627.45(50.1 \%)$ \\
\hline \multirow[t]{2}{*}{ Water } & 160.9 & - & - & - \\
\hline & Total: & 572 & & 1252 \\
\hline
\end{tabular}

Notes: *Estimated cost (assumed equal to fly ash cost); between parentheses is presented the weight (percentage) of each component in the total value.

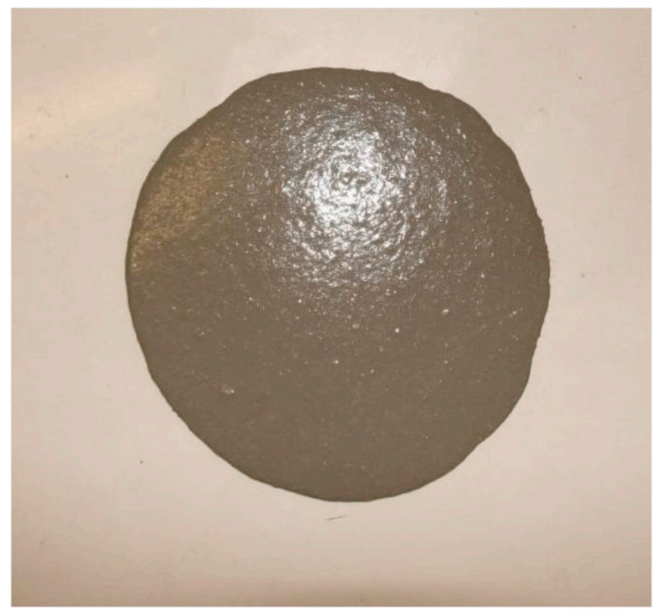

Fig. 9. Final spread area of UHPFRC without fibre agglomeration.

\subsection{Autogenous shrinkage evolution}

Fig. 10 shows the effect of adding 3\% steel micro fibres on autogenous shrinkage development of the UPHC mixture D. Since, steel microfibers partially replaced $3 \%$ of aggregates ( $85 \%$ sand $+15 \%$ ECat) there was no significant reduction in hydration activity (except for the reactions involving ECat), which is responsible for autogenous shrinkage. Thus, the observed reduction in autogenous shrinkage deformations is probably mainly due to the locally shrinkage-restraining effect of fibres [53]. As the matrix shrinks, shear stresses develop along steel microfibers, leading to compressive stresses in the microfibers and tensile stresses in the cementitious matrix [53]. The shrinkage-restraining effect of fibres is dependent on the elastic modulus of the fibres and matrix, and the fibres content and its aspect ratio [53].

\subsection{Mechanical performance}

Fig. 11a shows the compression results of the UHPFRC mixture undertaken on cubic specimens ( $50 \mathrm{~mm}$ ), at the ages of 2, 7, 28 and 90 days. The experimental results are plotted against the theoretical values computed as proposed by Graybeal using equation (3) [54] for untreated UHPFRC.

$f \mathcal{c}(t)=f_{\mathcal{c}^{\prime}}\left[1-\exp \left(-\left(\frac{t-0.9}{3}\right)^{0.6}\right)\right]$

where $f c^{\prime}$ is the 28-day compressive strength of untreated UHPFRC (147 MPa in the current study) and $t$ is the age. In general, a satisfactory level of consistency is observed between the theoretical values and the experimental results. The biggest difference is observed at the initial stage of the curve, namely at 2 days when the compressive strength is $34 \%$ higher than the predicted value using Eq. (3). UHPFRC specimens reached after 2 days casting $53 \%$ of the compressive strength at 90 days. This was followed by a less pronounced rate of compressive strength development in the subsequent days namely, being respectively at 7 days and 28 days after casting, $76 \%$ and $94 \%$ of the ultimate compressive strength.

From the original six dog-bone shaped specimens used in UTT only four were considered valid, e.g. those with a macro-crack localized within the measuring length covered by the LVDTs. Fig. 11b presents the individual results (black curves) and the respective average (red curve) for all valid tests. The differences among the curves can be explained by the well-known effect of fibre orientation [14]. In all of the individual curves, three main stages can be identified: elastic, hardening and softening. In the first stage, a linear elastic behaviour is observed until the first single micro-crack forms. After matrix cracking, an increase in stress was always observed, which is accompanied by the formation of multiple micro-cracks [14]. The last stage starts when a macro-crack localizes in one of the previously formed micro-cracks, being characterized by a decrease in stress. The softening stage is governed by fibre pull-out [14]. The obtained peak stresses and peak strains ranged from 11.4 to $15.1 \mathrm{MPa}$ and from 0.27 to $0.47 \%$, respectively, which compare well with results reported in the literature for UHPFRCs with other cementitious matrixes and same fibre content [14].

\subsection{Economic and environmental costs}

Table 9 shows the cost influence of each material on the final product using reference prices for the Portuguese market. While limestone filler, ECat and aggregate insignificantly influence the total costs, the

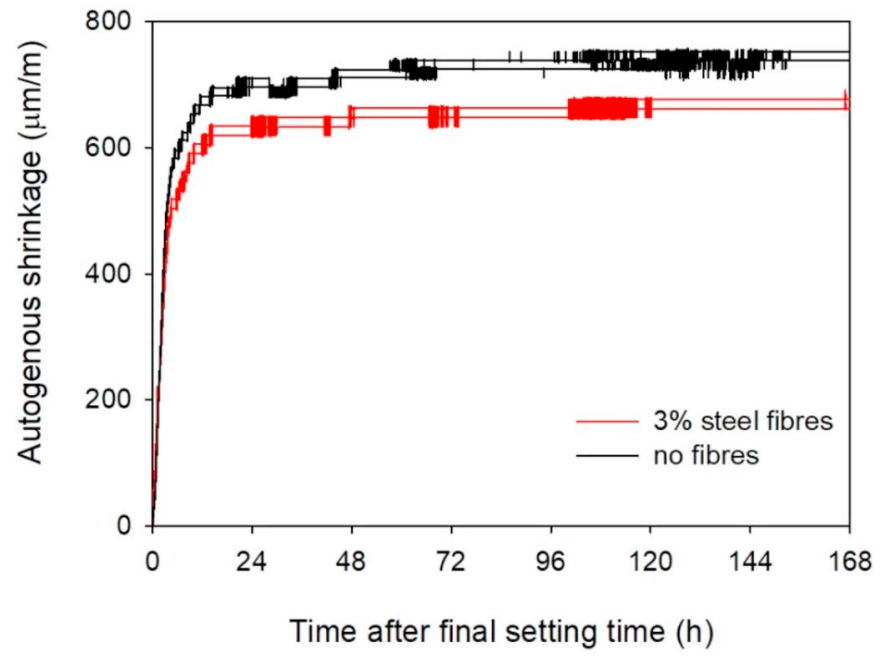

Fig. 10. Autogenous shrinkage evolution of mixture D with and without steel microfibers. 


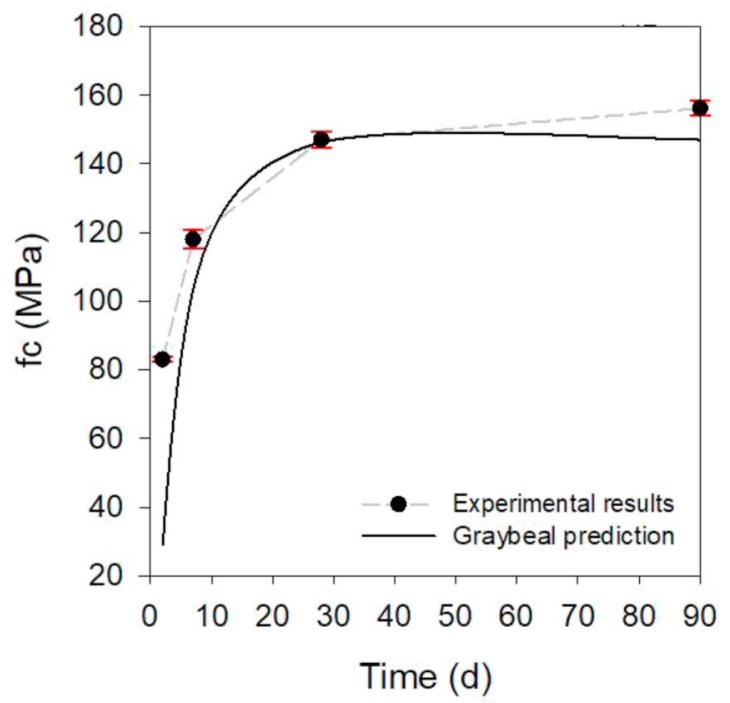

(a)

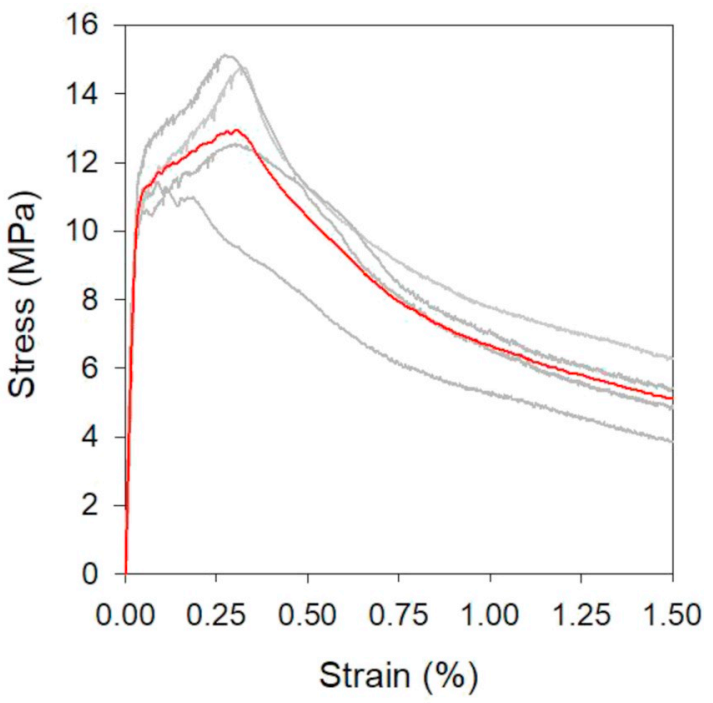

(b)

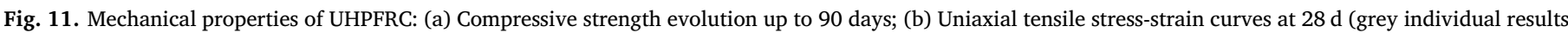
and red average result). (For interpretation of the references to colour in this figure legend, the reader is referred to the Web version of this article.)

costs of fibre reinforcement represent about $3 / 4$ the cost of UHPFRC. After the steel fibres, cement and silica fume represent the major proportion of the total cost. It is worth pointing that the total cost of the proposed UHPFRC mixture, of $572 € / \mathrm{m}^{3}$, is significantly lower than the price of commercial premixes currently marketed in Europe, of about $1000 € / \mathrm{m}^{3}$, not including the cost of fibres, aggregates, superplasticizer and water. Thus, the use of non-proprietary UHPC mixtures, like the one shown here, can represent an important competitive advantage for the construction sector.

The embedded $\mathrm{CO}_{2}$ emission of UHPFRC mixture was evaluated focusing on the amount of materials required for $1 \mathrm{~m}^{3}$ to demonstrate its eco-efficiency. Reference values of levels of embodied carbon dioxide in the concrete raw materials provided in Refs. [55-57] were used, as indicated in Table 9. Embodied carbon dioxide of ECat was considered null since according to the standard ISO 14044 [58] the allocation of environmental impacts of a recycling material is avoided when there is no changes of its inherent properties and it is used as a surrogate of a primary material. This is the case in the present study because ECat is being directly used in the UHPFRC composition with no additional processing step and representing a reduced demand of a natural resource, the sand.

The results for the estimation of the embedded $\mathrm{CO}_{2}$ emission of $1 \mathrm{~m}^{3}$ UHPFRC are presented in Table 9, along with the contribution of each material to the total value. $\mathrm{CO}_{2}$ emission of proposed UHPFRC is mainly due to the manufacture of micro steel fibres $(50.1 \%)$ and cement production (45.9\%).

Yu et al. [59], using data points from several different UHPCs from literature, found a trend line between the compressive strength and the embodied $\mathrm{CO}_{2}$ emissions (computed from the embodied $\mathrm{CO}_{2}$ values for each component of concrete). The straight line that represents this trend as well as the corresponding equation are illustrated in Fig. 12. Mixture D developed in the current study is below the trend line, which means that the designed UHPC has a lower environmental impact than other typical UHPC mixtures, being close to the eco-friendly UHPCs proposed by Yu et al. [59]. EUHPC-LP, EUHPC -FA and EUHPC - GGBS refer to different UHPC eco-mixes incorporating limestone powder, fly ash and ground granulated blast-furnace slag as cement replacement, respectively [59].

\section{Conclusions}

The current study revealed that spent equilibrium catalyst, a waste generated from oil refinery industry, can be turned into a value-added by-product when used as an internal curing agent to produce UHPFRC. Its use is not expected to affect the robustness of UHPFRC production since ECat is very well consistent regarding particle size distribution as well as physical and chemical composition among successive refinery deliveries.

Based on the mathematical empirical models derived from the DOE implementation, the following relationships between mix design variables and UHPC properties were established:

\subsection{UHPC flowability}

- Both $s f / c$ and $V_{w} / V_{p}$ have a significant positive influence on UHPC flowability

- The incorporation of ECat, as sand partial surrogate, besides extra water for ECat absorption, had only a slight negative effect on UHPC flowability

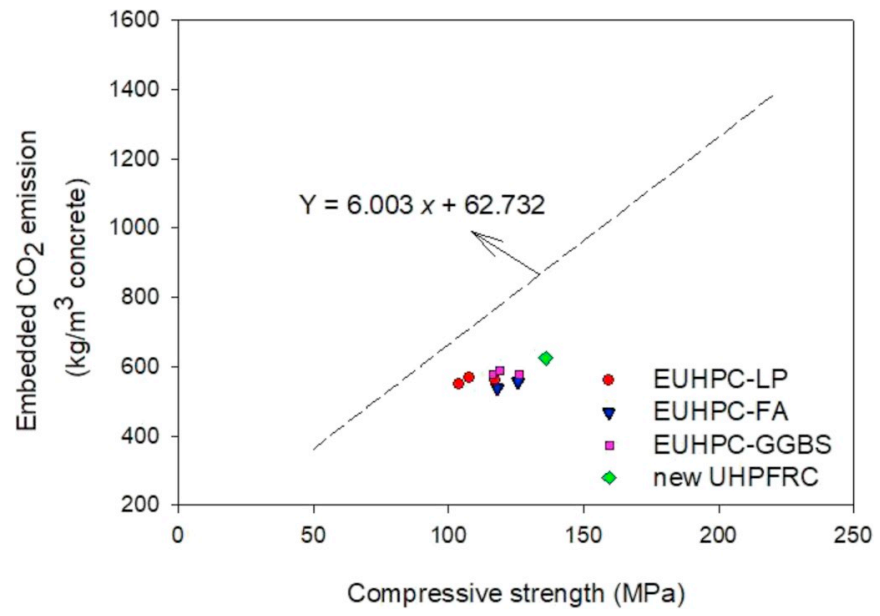

Fig. 12. Comparison of embedded $\mathrm{CO}_{2}$ emission of the developed Mixture D and other eco-friendly UHPCs (adapted from Ref. [59]). 


\subsection{UHPC final setting time}

- As expected, an increase of $V_{w} / V_{p}$ or $S p / p$, particularly for relatively high superplasticizer dosages as is the case in this study, retards the final setting time

- Replacement of sand with the ECat with huge specific surface area with water absorption ability led to a significant decrease in the final setting time

\subsection{UHPC autogenous shrinkage}

- An increase of $s f / c$ was found to significantly increase autogenous shrinkage. An opposing significant effect was found for $V_{E C a t} / V_{s}$, which proves its beneficial effect to mitigate autogenous shrinkage of UHPC attributed to the absorbed water in the porous ECat particles.

\subsection{UHPC resistivity and compressive strength}

- A negative effect of ECat incorporation was found on both UHPC resistivity and compressive strength at $28 \mathrm{~d}$ while $s f / c$ exhibited a significant positive effect on both these properties.

- An interaction effect $\left(V_{E C a t} / V_{s} \times s f / c\right)$ was also found to be significant to explain the resistivity at 28 days. The decrease in resistivity with an increase of $V_{E C a t} / V_{s}$ is stronger for higher values of $s f / c$.

- As expected, the resistivity at 28 days decreases with an increase of $V_{w} / V_{p}$

The optimal UHPC mixture that represents the best compromise between low autogenous shrinkage, at early ages, and high resistivity at 28 days, while guaranteeing sufficient deformability and compressive strength was found for: $\mathrm{Vw} / \mathrm{Vp}=0.394 ; \mathrm{Sp} / \mathrm{p}=2.0 \%$; $\mathrm{V}_{\mathrm{ECat}} /$ $\mathrm{V}_{\mathrm{s}}=0.15 ; \mathrm{Sf} / \mathrm{c}=0.049$ (and $\mathrm{w} / \mathrm{c}=0.25, \mathrm{Vs} / \mathrm{Vm}=0.39$ ). This optimal UHPC mixture contains $155 \mathrm{~kg} / \mathrm{m}^{3}$ of ECat that corresponds to $46.61 / \mathrm{m}^{3}$ of extra water required to saturate the ECat. This value is within the range of extra water absorbed for internal curing of UHPC by other materials which use as internal curing agents is already consolidate such as, SAPs $\left(33-561 / \mathrm{m}^{3}\right)$ [17] and LWS $\left(11-63 \mathrm{l} / \mathrm{m}^{3}\right)$ [15] and is higher than the total water absorbed by $220 \mathrm{~kg} / \mathrm{m}^{3}$ of RHA (about $18.91 / \mathrm{m}^{3}$ ) [9].

The optimal UHPC mixture resulted in a reduction of about $32 \%$ in autogenous shrinkage measured $20 \mathrm{~h}$ after final setting, compared to the mixture with the highest result of autogenous shrinkage in the experimental plan $(1011 \mu \mathrm{m} / \mathrm{m})$. The reduction of autogenous shrinkage is expected to result in proportionally lower self-induced stresses in the presence of external restraint, which might avoid cracking and/or allow for a reduction of fibre content in UHPFRC. Other properties influencing the development of self-induced stresses are the Young's modulus evolution and the tensile creep at early age, which however has not been investigated in the present study.

The UHPFRC mixture prepared combining the optimal UHPC mixture with $3 \%$ high-strength steel fibres $\left(l_{\mathrm{f}} / \mathrm{d}_{\mathrm{f}}=65\right)$ :

- exhibited a compressive strength of 147 and $156 \mathrm{MPa}$ after 28 and 90 days of wet curing, respectively

- exhibited a uniaxial tensile peak stress and peak strain ranging from 11 to $15 \mathrm{MPa}$ and $0.27-0.47 \%$, respectively, at 28 days

- proved to be more eco-efficient and more cost efficient than typical UHPFRCs reported in the literature, with same fibre content.

\section{Acknowledgements}

This work was financially supported by: UID/ECI/04708/2019CONSTRUCT - Instituto de I\&D em Estruturas e Construções funded by national funds through the FCT/MCTES (PIDDAC); by the project POCI-
01-0145-FEDER-031777 - "UHPGRADE - Next generation of ultra-high performance fibre-reinforced cement based composites for rehabilitation and strengthening of the existing infrastructure" funded by FEDER funds through COMPETE2020 - Programa Operacional Competitividade e Internacionalização (POCI) and by national funds (PIDDAC) through FCT/MCTES; and by FCT - Fundação para a Ciência e a Tecnologia through the $\mathrm{PhD}$ scholarship $\mathrm{PD} / \mathrm{BD} / 113636 / 2015$, attributed within the Doctoral Program in Eco-Efficient Construction and Rehabilitation (EcoCoRe). Collaboration and materials supply by Sines Refinery/Galp Energia, Secil, Omya Comital, Sika, Bekaert and EUROMODAL is gratefully acknowledged. This study builds upon research developed in ECO-Zement R\&D + i project which was awarded with the Jerónimo Martins/Green Project Awards 2017.

We appreciate the helpful comments and suggestions of the anonymous referees.

\section{References}

[1] Z.B. Haber, I.D. la Varga, B.A. Graybeal, Properties and Behavior of UHPC-Class Materials (FHWA-HRT-18-036), (2018).

[2] C. Shi, Z. Wu, J. Xiao, D. Wang, Z. Huang, Z. Fang, A review on ultra high performance concrete: Part I. Raw materials and mixture design, Constr. Build. Mater. 101 (2015) 741-751, https://doi.org/10.1016/j.conbuildmat.2015.10.088.

[3] E. Fehling, M. Schmidt, J. Walraven, T. Leutbecher, S. Frohlich, Ultra-High Performance Concrete UHPC: Fundamentals, Design, Examples, Ernst \& Sohn, Wiley, Berlin, Germany, 2014, https://doi.org/10.1017/СBO9781107415324.004.

[4] S.A. Miller, Supplementary cementitious materials to mitigate greenhouse gas emissions from concrete: can there be too much of a good thing? J. Clean. Prod. 178 (2018) 587-598, https://doi.org/10.1016/j.jclepro.2018.01.008.

[5] R. Yu, P. Spiesz, H.J.H. Brouwers, Mix design and properties assessment of ultrahigh performance fibre reinforced concrete (UHPFRC), Cement Concr. Res. 56 (2014) 29-39, https://doi.org/10.1016/j.cemconres.2013.11.002.

[6] S.A. Miller, V.M. John, S.A. Pacca, A. Horvath, Carbon dioxide reduction potential in the global cement industry by 2050, Cement Concr. Res. (2017) 1-10, https:// doi.org/10.1016/j.cemconres.2017.08.026.

[7] T. Wierzbicki, Assessment and Rehabilitation of Central European Highway Structures - ARCHES Executive Summary Report Iv, Brussels, Belgium, (2010).

[8] W. Huang, H. Kazemi-Kamyab, W. Sun, K. Scrivener, Effect of cement substitution by limestone on the hydration and microstructural development of ultra-high performance concrete (UHPC), Cement Concr. Compos. 77 (2017) 86-101, https://doi. org/10.1016/j.cemconcomp.2016.12.009.

[9] N. Van Tuan, Rice Husk Ash as a Mineral Admixture for Ultra High Performance Concrete, Delft University of Technology, 2011.

[10] A. Tafraoui, G. Escadeillas, T. Vidal, Durability of the ultra high performances concrete containing metakaolin, Constr. Build. Mater. 112 (2016) 980-987, https:// doi.org/10.1016/j.conbuildmat.2016.02.169.

[11] N.A. Soliman, A. Tagnit-Hamou, Partial substitution of silica fume with fine glass powder in UHPC: filling the micro gap, Constr. Build. Mater. 139 (2017) 374-383, https://doi.org/10.1016/j.conbuildmat.2017.02.084.

[12] Ana Mafalda Matos, Sandra Nunes, Carla Costa, Mitigation of early age shrinkage of UHPFRC by using spent equilibrium catalyst, Int. RILEM Conf. Mater. Syst. Struct. Civ. Eng. 2016 Segm. Serv. Life Cem. Mater. Struct., Lyngby, Denmark, 2016.

[13] P.F. Jensen, O. Mejlhede, Hansen, Autogenous deformation and change of the relative humidity in silica fume-modified cement paste, ACI Mater. J. 93 (1996) 539-543.

[14] A. Abrishambaf, M. Pimentel, S. Nunes, Influence of fibre orientation on the tensile behaviour of ultra-high performance fibre reinforced cementitious composites, Cement Concr. Res. 97 (2017) 28-40, https://doi.org/10.1016/j.cemconres.2017. 03.007.

[15] W. Meng, K. Khayat, Effects of saturated lightweight sand content on key characteristics of ultra-high-performance concrete, Cement Concr. Res. 101 (2017) 46-54, https://doi.org/10.1016/j.cemconres.2017.08.018.

[16] V. Mechtcherine, H.-W. Reinhardt (Eds.), Application of Superabsorbent Polymers (SAP) in Concrete Construction. State of the Art Report Prepared by Technical Committee 225-SAP, Springer, 2012.

[17] L. Dudziak, V. Mechtcherine, Reducing the cracking potential of ultra-high performance concrete by using Super Absorbent Polymers (SAP), Adv. Cem. Mater. Proc. Int. Conf. Adv. Concr. Mater. (2010) 11-19.

[18] J. Justs, M. Wyrzykowski, D. Bajare, P. Lura, Internal curing by superabsorbent polymers in ultra-high performance concrete, Cement Concr. Res. 76 (2015) 82-90, https://doi.org/10.1016/j.cemconres.2015.05.005.

[19] X. Wang, R. Yu, Z. Shui, Q. Song, Z. Zhang, Mix design and characteristics evaluation of an eco-friendly Ultra-High Performance Concrete incorporating recycled coral based materials, J. Clean. Prod. 165 (2017) 70-80 https://doi.org/10.1016/j. jclepro. 2017.07.096.

[20] M.A.A. Aldahdooh, N. Muhamad Bunnori, M.A. Megat Johari, Influence of palm oil fuel ash on ultimate flexural and uniaxial tensile strength of green ultra-high performance fiber reinforced cementitious composites, Mater. Des. 54 (2014) 694-701 https://doi.org/10.1016/j.matdes.2013.08.094.

[21] V.T.A. Van, C. Rößler, D.D. Bui, H.M. Ludwig, Rice husk ash as both pozzolanic 
admixture and internal curing agent in ultra-high performance concrete, Cement Concr. Compos. 53 (2014) 270-278, https://doi.org/10.1016/j.cemconcomp.2014. 07.015.

[22] E.T.C. Vogt, B.M. Weckhuysen, Fluid catalytic cracking: recent developments on the grand old lady of zeolite catalysis, Chem. Soc. Rev. 44 (2015) 7342-7370, https:// doi.org/10.1039/c5cs00376h.

[23] R. Sadeghbeigi, Fluid Catalytic Cracking Handbook: an Expert Guide to the Practical Operation, Design, and Optimization of FCC Units, second ed., Gulf Professional Publishing, 2000.

[24] N.T. Castellanos, J.T. Agredo, Using spent fluid catalytic cracking (FCC) catalyst as pozzolanic addition - a review, Ing. Invest. 30 (2010) 35-42.

[25] F. Ferella, V. Innocenzi, F. Maggiore, Oil refining spent catalysts: a review of possible recycling technologies, Resour. Conserv. Recycl. 108 (2016) 10-20, https:// doi.org/10.1016/j.resconrec.2016.01.010.

[26] J. Payá, J. Monzó, M.V. Borrachero, S. Velázquez, Cement equivalence factor evaluations for fluid catalytic cracking catalyst residue, Cement Concr. Compos. 39 (2013) 12-17, https://doi.org/10.1016/j.cemconcomp.2013.03.011.

[27] J. Paya, J. Monzó, M. V Borrachero, S. Velázquez, M. Bonilla, Determination of the pozzolanic activity of fluid catalytic cracking residue. Thermogravimetric analysis studies on FC3R - lime pastes, Cem. Consrete Res. 33 (2003) 1085-1091, https:// doi.org/10.1016/S0008-8846(03)00014-0.

[28] A. Allahverdi, S. Vakilinia, P. Gharabeglu, Effects of RFCC spent catalyst on some physicomechanical properties of portland cement paste, Ceram. - Silikáty. 55 (2011) 161-168.

[29] K. Al-Jabri, M. Baawain, R. Taha, Z.S. Al-Kamyani, K. Al-Shamsi, A. Ishtieh, Potential use of FCC spent catalyst as partial replacement of cement or sand in cement mortars, Constr. Build. Mater. 39 (2013) 77-81, https://doi.org/10.1016/j. conbuildmat.2012.05.035.

[30] N. Su, Z.-H. Chen, H.-Y. Fang, Reuse of spent catalyst as fine aggregate in cement mortar, Cement Concr. Compos. 23 (2001) 111-118, https://doi.org/10.1016/ S0958-9465(00)00074-3.

[31] R. Neves, C. Vicente, A. Castela, M.F. Montemor, Durability performance of concrete incorporating spent fluid cracking catalyst, Cement Concr. Compos. 55 (2015) 308-314, https://doi.org/10.1016/j.cemconcomp.2014.09.018.

[32] C. Costa, M.S. Ribeiro, N. Brito, Effect of waste oil-cracking catalyst incorporation on durability of mortars, Mater. Sci. Appl. 5 (2014) 905-914, https://doi.org/10. 4236/msa.2014.513092.

[33] C. Costa, P. Marques, Low-carbon cement with waste oil-cracking catalyst incorporation, IEEE-IAS/PCA 54th Cement Ind. Tech. Conf. (2012), http:// repositorio.ipl.pt/handle/10400.21/1836 , Accessed date: 14 April 2016.

[34] E.C. Torregrosa, Dosage Optimization and Bolted Connections for UHPFRC Ties, Universitat Politècnica de València, 2013.

[35] E. Brühwiler, E. Denarié, Rehabilitation and strengthening of concrete structures using ultra-high performance fibre reinforced concrete, Struct. Eng. Int. 4 (2013) 450-457, https://doi.org/10.2749/101686613X13627347100437.

[36] LNEC, E-64, Cements. Determination of Density [In Portuguese], (1979), pp. 1-2.

[37] D.C. Montgomery, Design and Analysis of Experiments, eighth ed., John Wiley \& Sons, Inc., Hoboken, 2012, https://doi.org/10.1198/tech.2006.s372.

[38] K.H. Khayat, A. Ghezal, M.S. Hadriche, Utility of statistical models in proportioning self-consolidating concrete, Mater. Struct. 33 (2000) 338-344, https://doi.org/10. 1007/BF02479705.

[39] A.M. Matos, L. Maia, S. Nunes, P. Milheiro-Oliveira, Design of self-compacting highperformance concrete: study of mortar phase, Constr. Build. Mater. 167 (2018) 617-630, https://doi.org/10.1016/j.conbuildmat.2018.02.053.

[40] F. Bayramov, C. Taşdemir, M. Taşdemir, Optimisation of steel fibre reinforced concretes by means of statistical response surface method, Cement Concr. Compos. 26 (2004) 665-675, https://doi.org/10.1016/S0958-9465(03)00161-6.

[41] M.A.A. Aldahdooh, N. Muhamad Bunnori, M.A. Megat Johari, Evaluation of ultra- high-performance-fiber reinforced concrete binder content using the response surface method, Mater. Des. 52 (2013) 957-965, https://doi.org/10.1016/j.matdes. 2013.06.034.

[42] I. Ferdosian, A. Camões, Eco-efficient ultra-high performance concrete development by means of response surface methodology, Cement Concr. Compos. 84 (2017) 146-156, https://doi.org/10.1016/j.cemconcomp.2017.08.019.

[43] M.A. Mosaberpanah, O. Eren, $\mathrm{CO} 2$ full factorial optimization of an ultra-high performance concrete mix design, Eur. J. Environ. Civ. Eng. 22 (2018) 450-463, https://doi.org/10.1080/19648189.2016.1210030.

[44] State-Ease Corporation. Design-expert software. https://www.statease.com/.

[45] V.G. Papadakis, Experimental investigation and theoretical modeling of silica fume activity in concrete, Cement Concr. Res. 29 (1999) 79-86, https://doi.org/10. 1016/S0008-8846(98)00171-9.

[46] D. Snoeck, O.M. Jensen, N. De Belie, The influence of superabsorbent polymers on the autogenous shrinkage properties of cement pastes with supplementary cementitious materials, Cement Concr. Res. 74 (2015) 59-67, https://doi.org/10. 1016/j.cemconres.2015.03.020.

[47] R.B. Polder, Test methods for on site measurement of resistivity of concrete - a RILEM TC-154 technical recommendation, Constr. Build. Mater. 15 (2001) 125-131, https://doi.org/10.1016/S0950-0618(00)00061-1.

[48] C.G. Berrocal, K. Hornbostel, M.R. Geiker, I. Löfgren, K. Lundgren, D.G. Bekas, Electrical resistivity measurements in steel fibre reinforced cementitious materials, Cement Concr. Compos. 89 (2018) 216-229, https://doi.org/10.1016/j. cemconcomp.2018.03.015.

[49] H. Huang, G. Ye, Examining the "time-zero" of autogenous shrinkage in high/ultrahigh performance cement pastes, Cement Concr. Res. 97 (2017) 107-114, https:// doi.org/10.1016/j.cemconres.2017.03.010.

[50] K. Wille, C. Boisvert-Cotulio, Material efficiency in the design of ultra-high performance concrete, Constr. Build. Mater. 86 (2015) 33-43, https://doi.org/10. 1016/j.conbuildmat.2015.03.087.

[51] S. Nunes, C. Costa, Numerical optimization of self-compacting mortar mixture containing spent equilibrium catalyst from oil refinery, J. Clean. Prod. 158 (2017) 109-121, https://doi.org/10.1016/j.jclepro.2017.04.161.

[52] C.A. Marchão, S.B. Nunes, V.G. Lúcio, A.A. Bras, J.A. Figueiras, Development and application of a high performance fibre reinforced self-compacting concrete in posttensioning anchorage zones, BEFIB2012 - Fibre Reinf. Concr., Guimarães, Portugal, 2012, pp. 1-12.

[53] A. Arbor, A. Arbor, Influences of fibers on drying shrinkage of fiber-reinforced cementitious composite, J. Eng. Mech. 127 (2001) 37-44.

[54] D.-Y. Yoo, N. Banthia, Mechanical properties of ultra-high-performance fiber-reinforced concrete: a review, Cement Concr. Compos. 73 (2016) 267-280, https:// doi.org/10.1016/j.cemconcomp.2016.08.001.

[55] T. Stengel, P. Schießl, Life cycle assessment (LCA) of ultra high performance concrete (UHPC) structures, Eco-Efficient Constr. Build. Mater. Elsevier, 2014, pp. 528-564, , https://doi.org/10.1533/9780857097729.3.528.

[56] M.U. Hossain, C.S. Poon, Y.H. Dong, D. Xuan, Evaluation of environmental impact distribution methods for supplementary cementitious materials, Renew. Sustain. Energy Rev. 82 (2018) 597-608, https://doi.org/10.1016/j.rser.2017.09.048.

[57] H.S. Müller, M. Haist, M. Vogel, Assessment of the Sustainability Potential of Concrete and Concrete Structures Considering Their Environmental Impact, Performance and Lifetime, (2014), https://doi.org/10.1016/j.conbuildmat.2014. 01.039.

[58] ISO 14044, Environmental Management. Life Cycle Assessment. Requirements and guidelines., (2006), (2006), pp. 1-46.

[59] R. Yu, P. Spiesz, H.J.H. Brouwers, Development of an eco-friendly Ultra-High Performance Concrete (UHPC) with efficient cement and mineral admixtures uses, Cement Concr. Compos. 55 (2015) 383-394, https://doi.org/10.1016/j. cemconcomp.2014.09.024. 